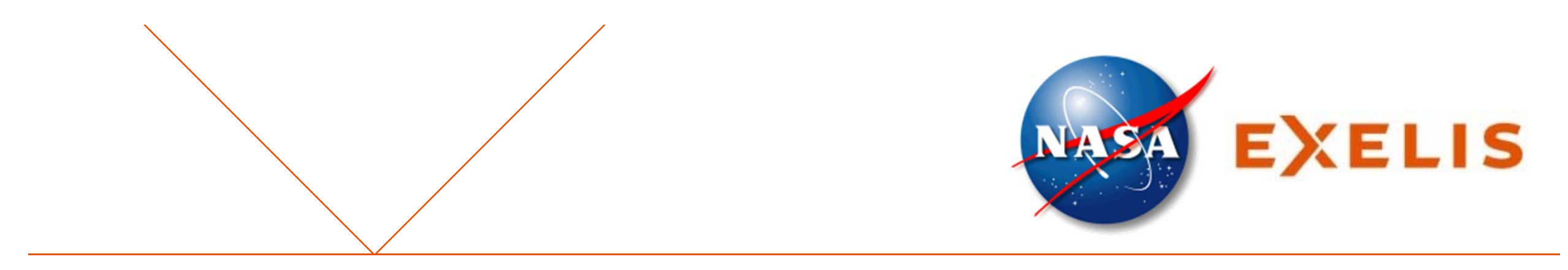

\title{
Processing of a stacked core mirror for UV applications [8837-10]
}

Gary W. Matthews, Charles S. Kirk, Steven P. Maffett and Calvin E. Abplanalp

Exelis Inc.

H. Philip Stahl, Ron Eng, William R. Arnold Sr.

NASA Marshall Space Flight Center

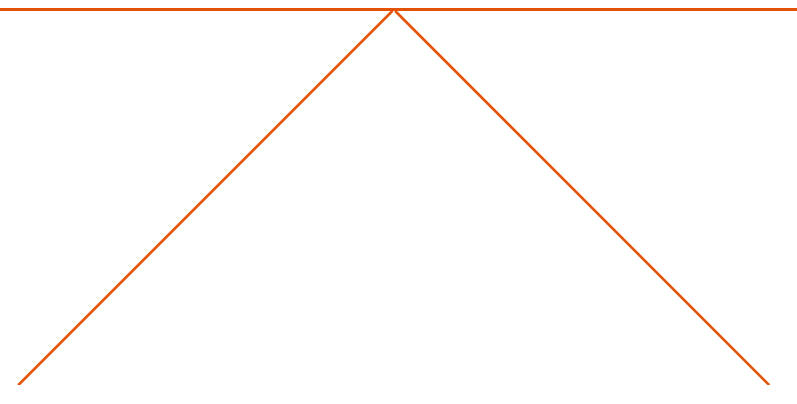

Work completed under NASA contract number NNM12AA02C 


\section{Advanced UVOIR Mirror Technology Development (AMTD) Program}

- Develop mirror blank technology applicable to building a cost effective, large $(4 \mathrm{~m}-8 \mathrm{~m}$ class), passive, monolithic mirror capable of imaging in the UV spectrum

- $0.43 m$ demonstration mirror fabricated

- $5.5 \mathrm{~nm}$ RMS overall surface figure demonstrated

- Current limitations regarding a $4 \mathrm{~m}$ class mirror

- Significant mirror depth required to achieve stiffness

- Core depth drives up cutting costs, schedule, risk, and areal density

- Stack sealing of boules to achieve overall depth is very expensive and time consuming

- AMTD program addresses these issues to reduce the cost and lead time for building a $4 \mathrm{~m}$ class mirror blank and demonstrates the ability to polish and test the blank to UV quality 


\section{Large Lightweight ULE ${ }^{\circledR}$ Primary Mirrors at Exelis}

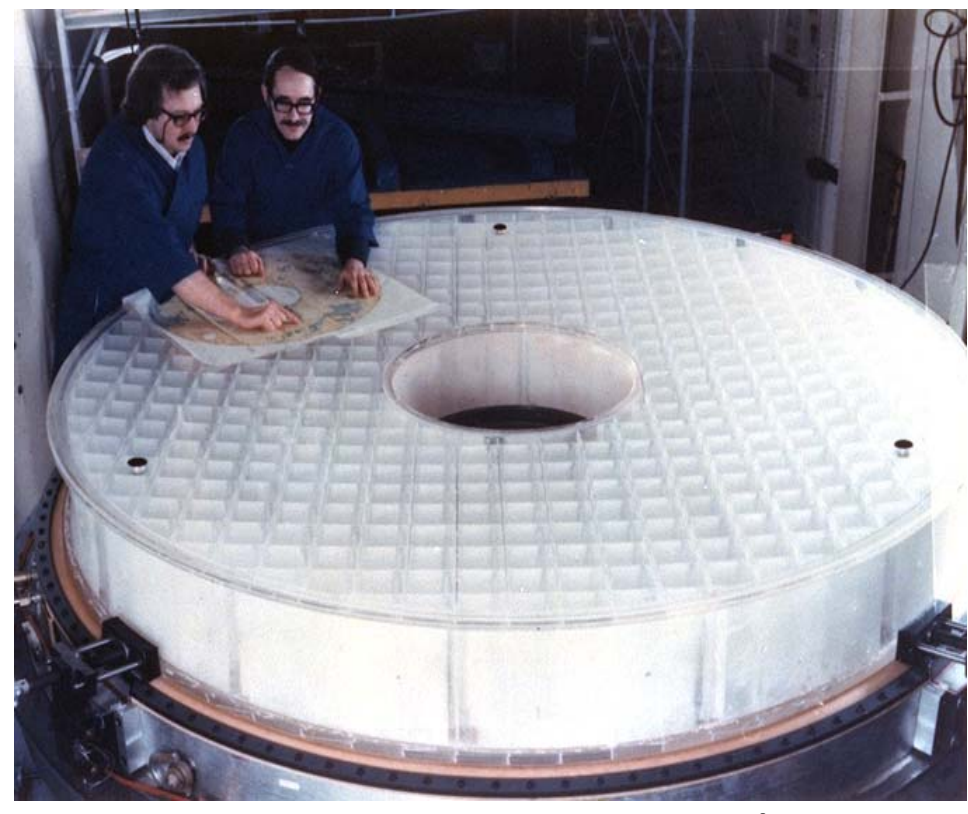

High Temperature Fusion - 1970's

(Hubble Primary Mirror)

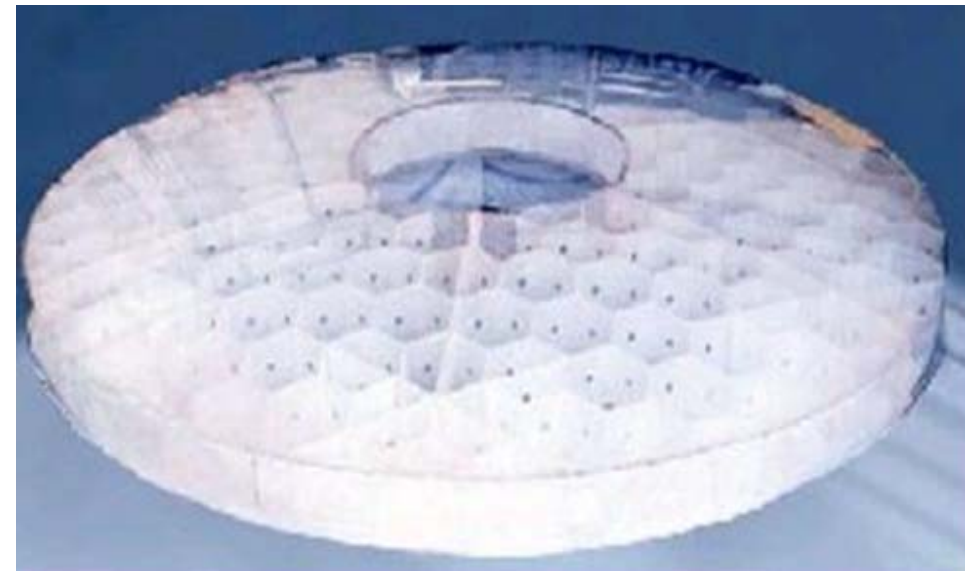

ATT - Waterjet Cut Core - Low Temp Fusion - 1990's

NASA EXELIS

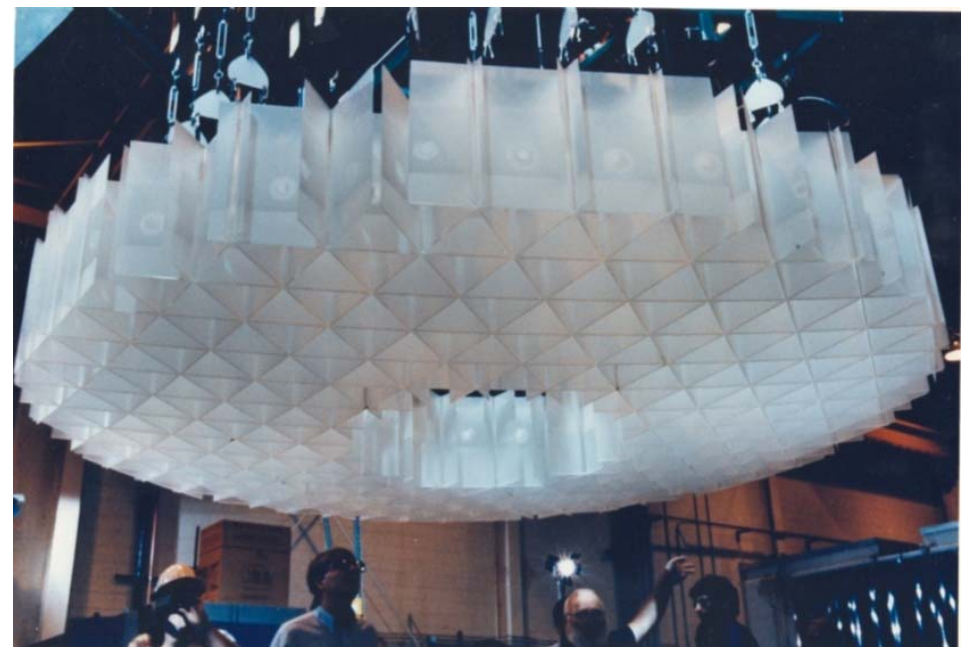

Frit Technology with Flame Welded Core - 1980's

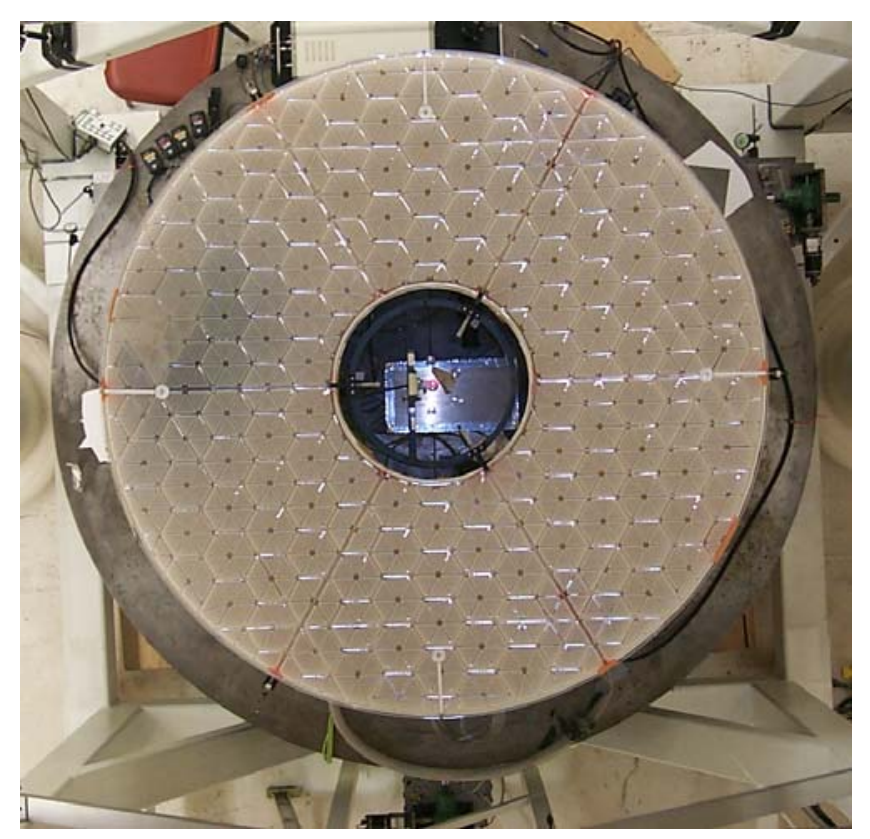

Primary Mirror - Low Temp Fusion - 2000's 


\section{4m Mirror Concept}

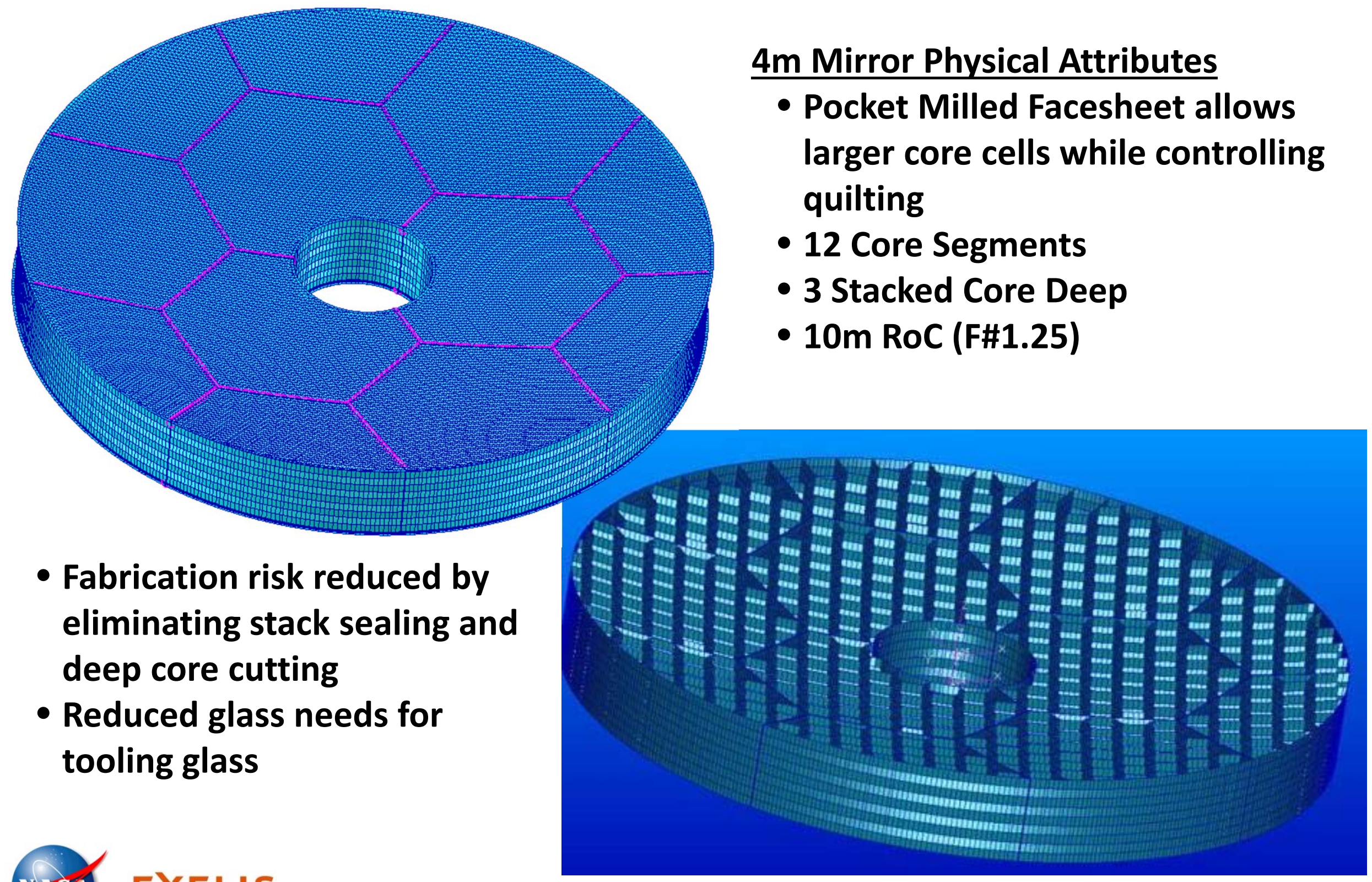




\section{AMTD 8m Mirror Design and Analysis \\ is}

- Stacked core and Pocket milled facesheet design

- $24.2 \mathrm{~m}$ RoC (f\#1.5)

- The 8 meter mirror modeled to assess performance

- Model includes lightweighted face plates joined to a light-weighted core.

- $5 \%$ additional mass added to light-weighted sections to account for corner radii.

- Total mass was 3042 kg, $60 \mathrm{~kg} / \mathrm{m}^{2}$

- First Free-Free mode at $33 \mathrm{~Hz}$

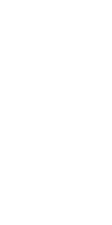

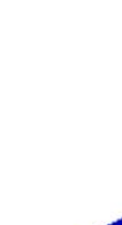

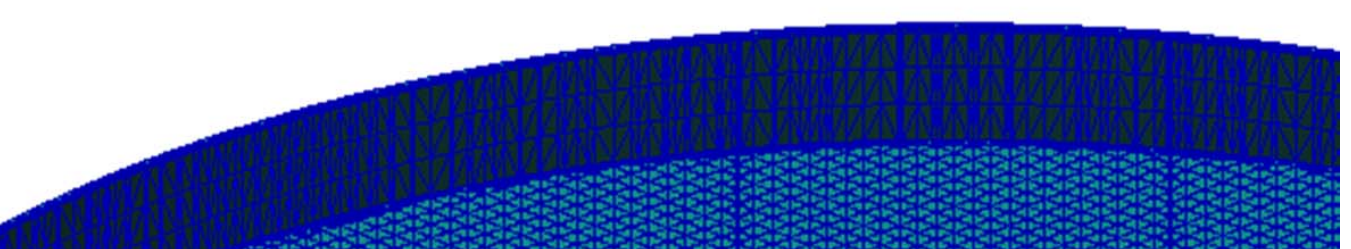

.
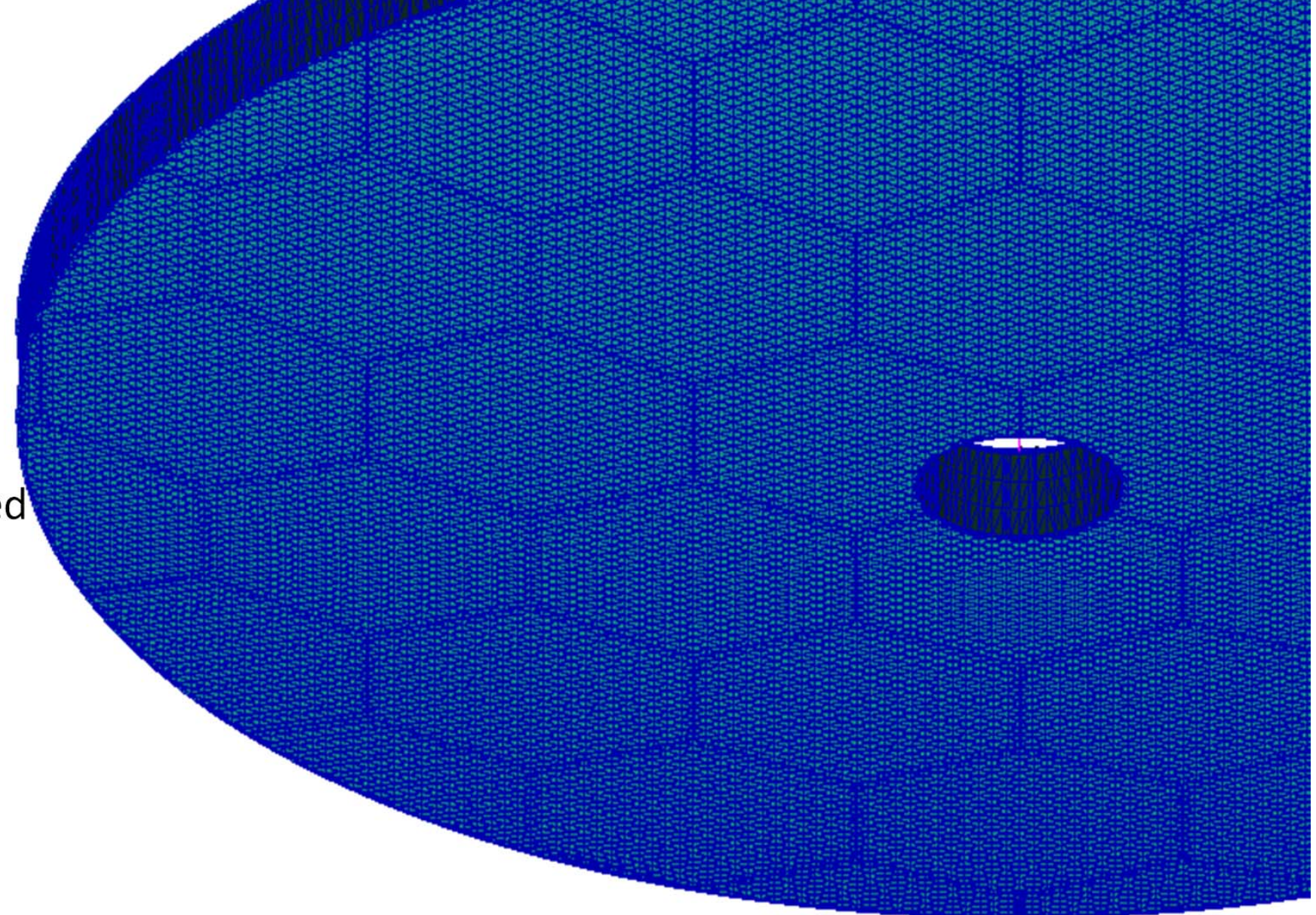


\section{AMTD is Developing Technologies for Near Term Large}

\section{Lightweight Primary Mirrors}

Stacked core

$>$ Core segments are fabricated from standard thickness boules, then stacked \& fused during blank assembly to achieve a deep core

$>$ Eliminates need for stack sealing of boules and deep AWJ cutting of cores

$>$ Enables lighter weight cores and reduces cost \& schedule for blank fab

Deep AWJ Cutting

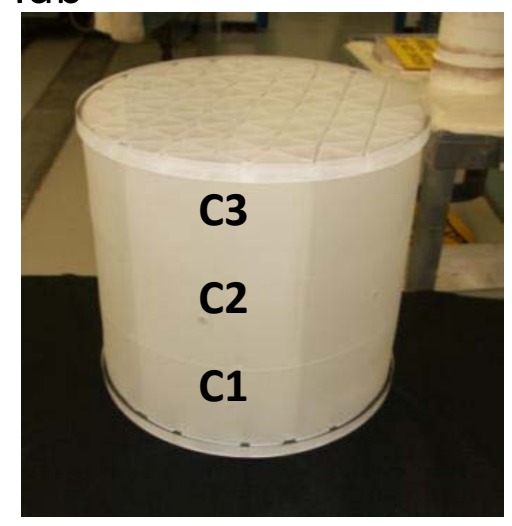

$>$ Extend AWJ cutting depth for LW cores from current $300 \mathrm{~mm}$ (11.6 in) up to $480 \mathrm{~mm}$ (19 in) depending on mirror stiffness

$>$ More difficult to control exit surface parameters
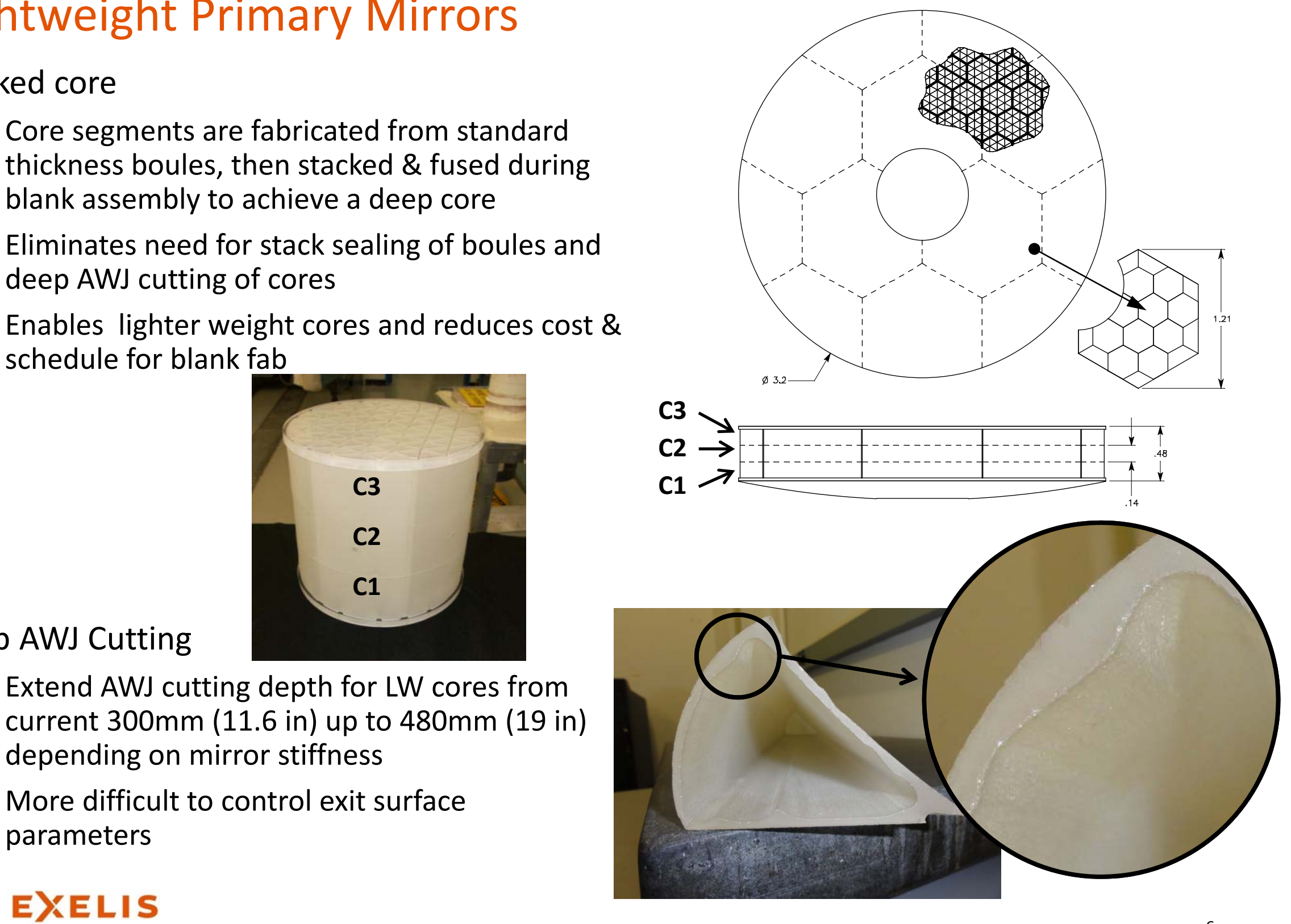


\section{Stacked Core Mirror Demonstration}

$0.4 \mathrm{~m}$ Demonstration part fabricated

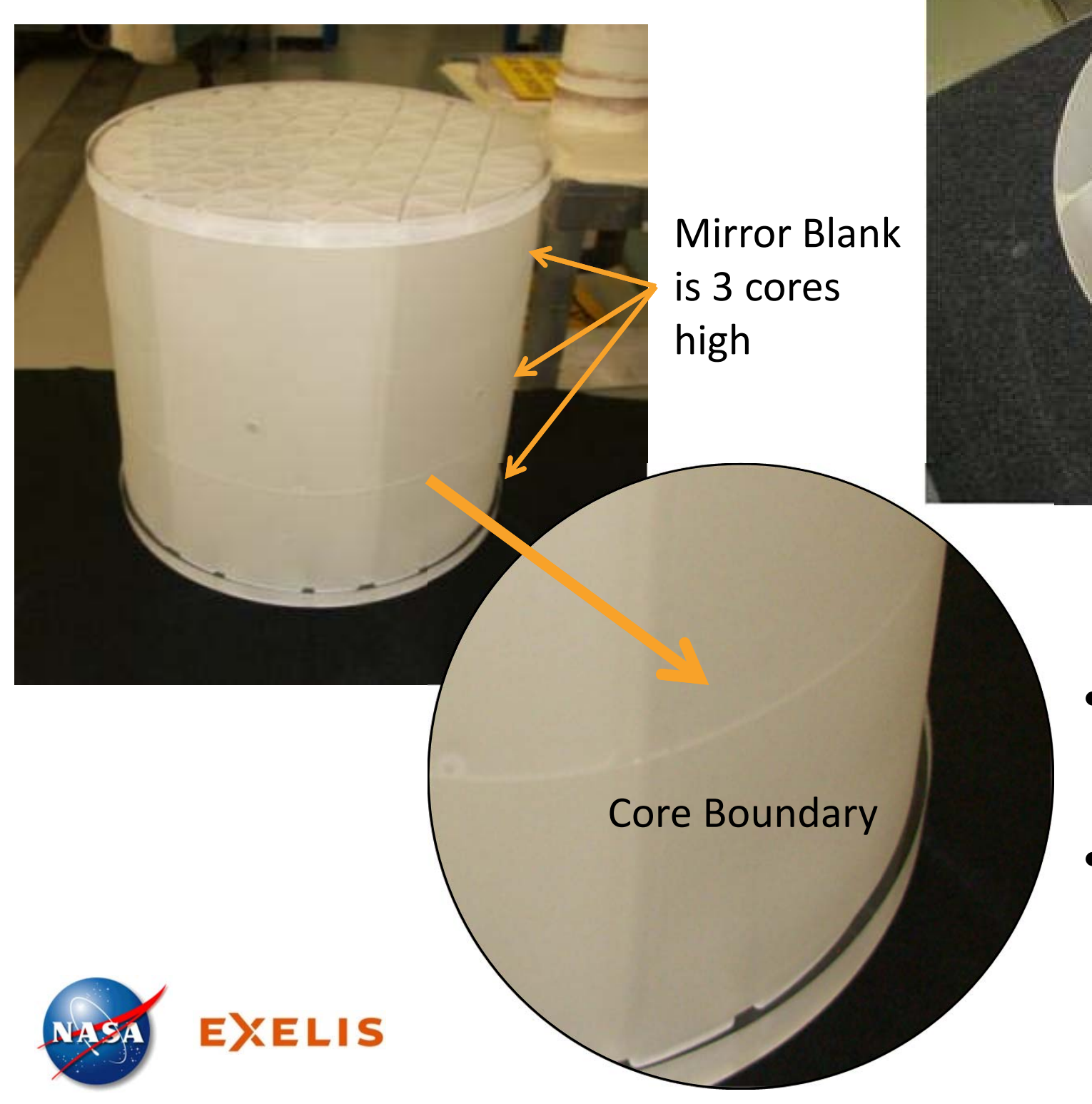

- The individual core segment surfaces are polished and AWJ just like traditional LTF mirrors

- During Low Temperature Fusion (LTF), the faceplates and the core segments are fused together (CoFired)

Single Mirror Core

(Note large cell size) 


\section{Faceplate Pocket Milling}

- Pocket milled facesheets have been used on other mirrors to provide additional stiffness between cell supports

- Allow for much larger core cell size to reduce overall areal density

- Extended to 24 pockets to enhance UV performance
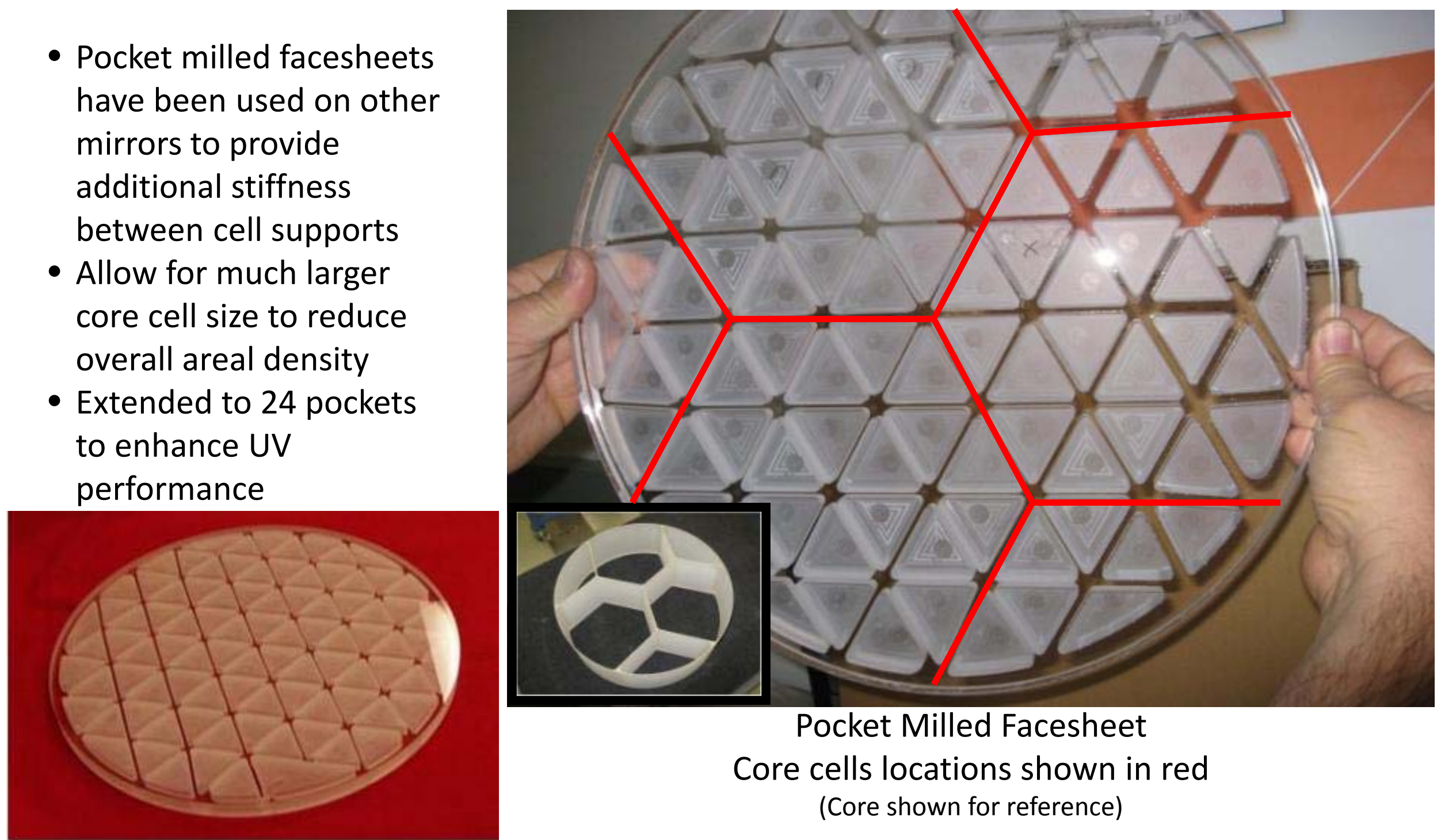

\section{Pocket Milled Facesheet}

Core cells locations shown in red (Core shown for reference)

Pocket Milled Facesheet 


\section{Processing Quality}

Processing completed to demonstrate that UV quality ( $5 \mathrm{~nm}$ RMS) could be achieved

Multiple orientation test minimized test errors and analytical backouts

$>$ Some minimal trefoil did not cancel out during testing

$>$ Mount repeatability ultimately limited final performance
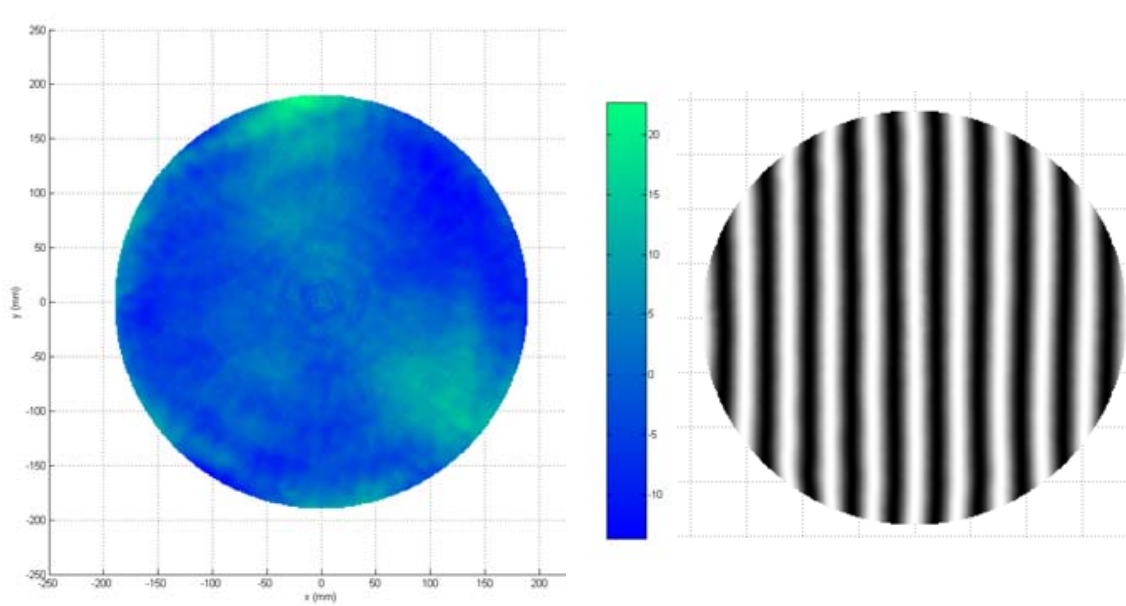

Final Optical Test $-5.5 \mathrm{~nm}$ RMS

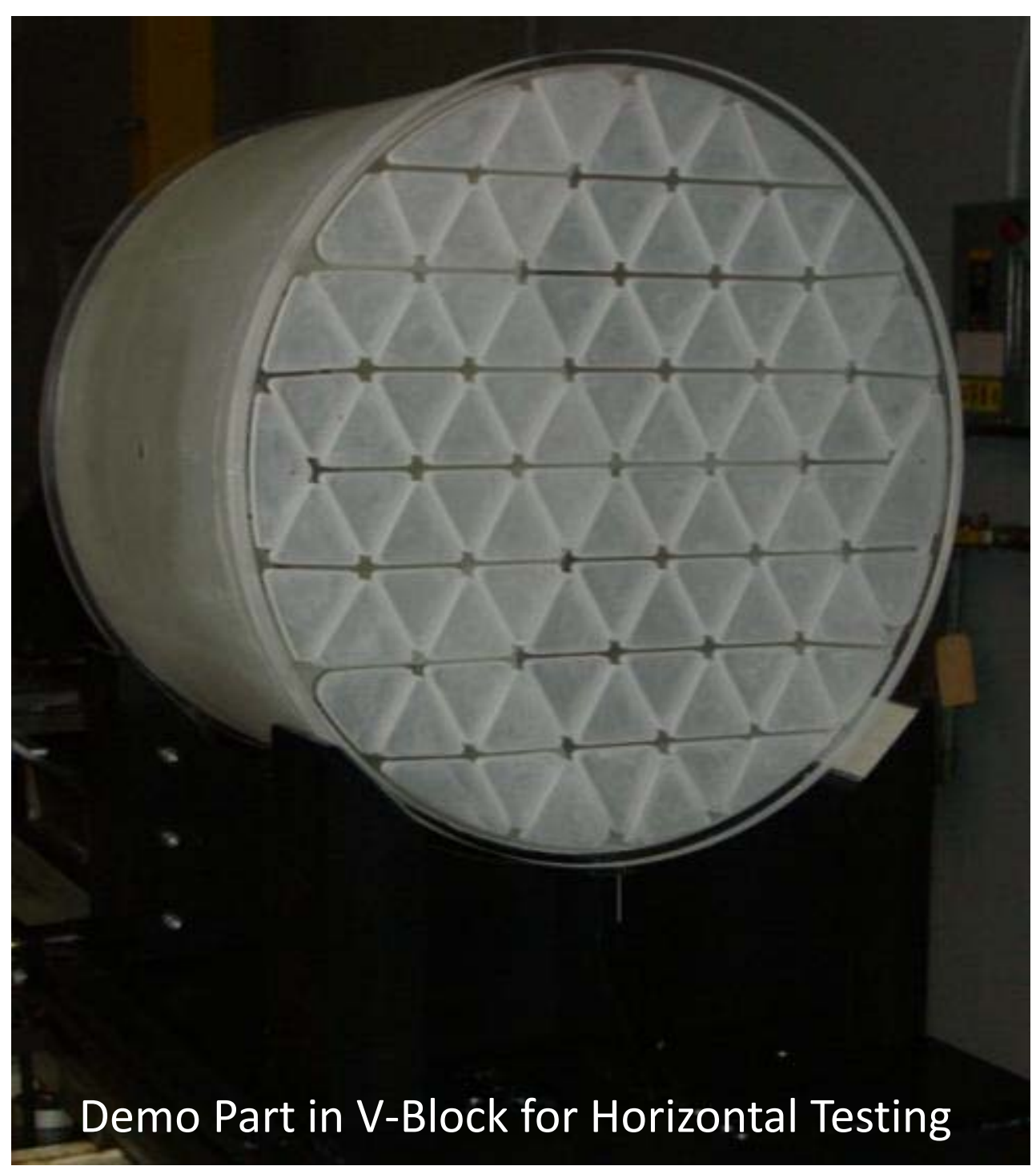

Demo Part in V-Block for Horizontal Testing 


\section{First Light Test}

117nm RMS - 524nm P-V

Power Removed
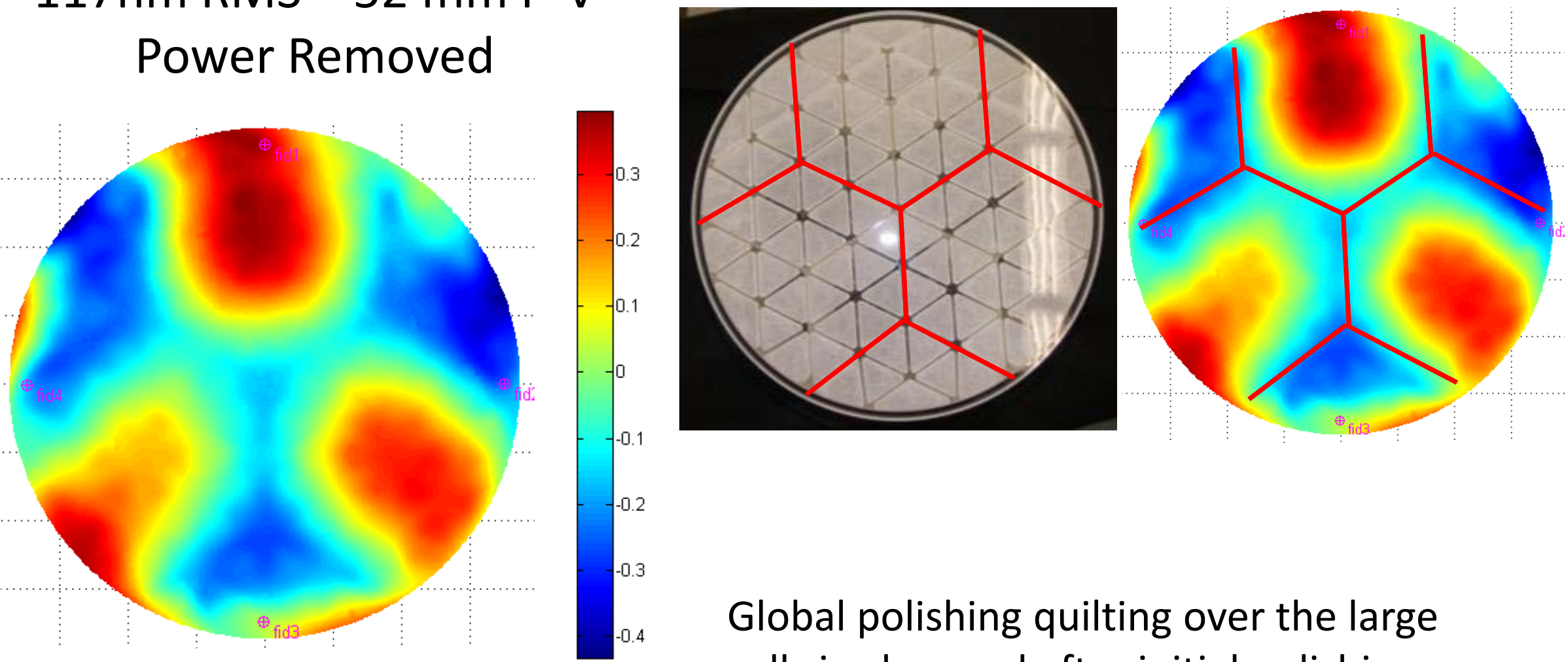

Global polishing quilting over the large cells is observed after initial polishing 


\section{Post Ion Figuring \#1}

\section{6nm RMS - 87nm P-V \\ Power Removed}
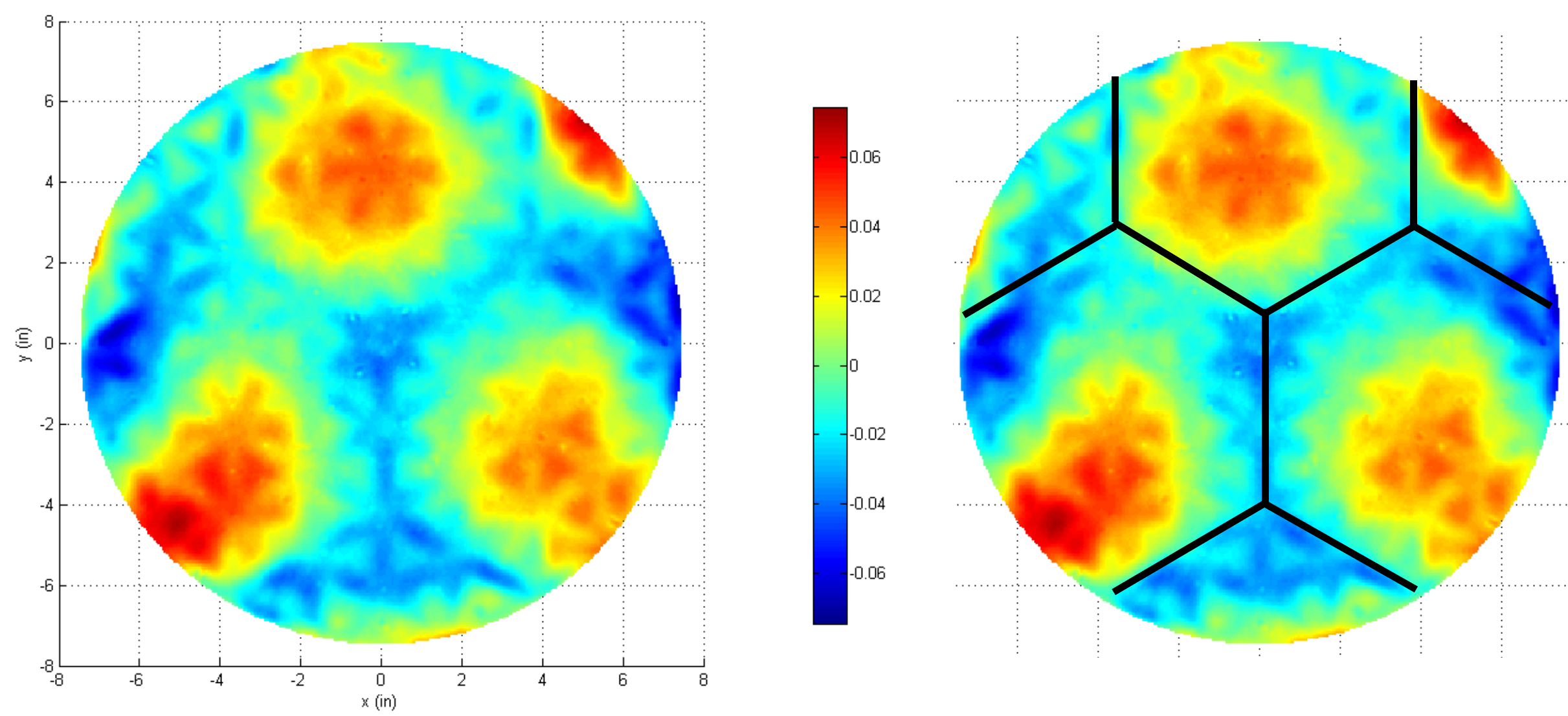

- First ion cycle greatly reduced the global figure error by $86 \%$.

- Some cell quilting still visible 
Post Ion Figuring \#2

\section{9nm RMS - 37nm P-V \\ Power Removed}

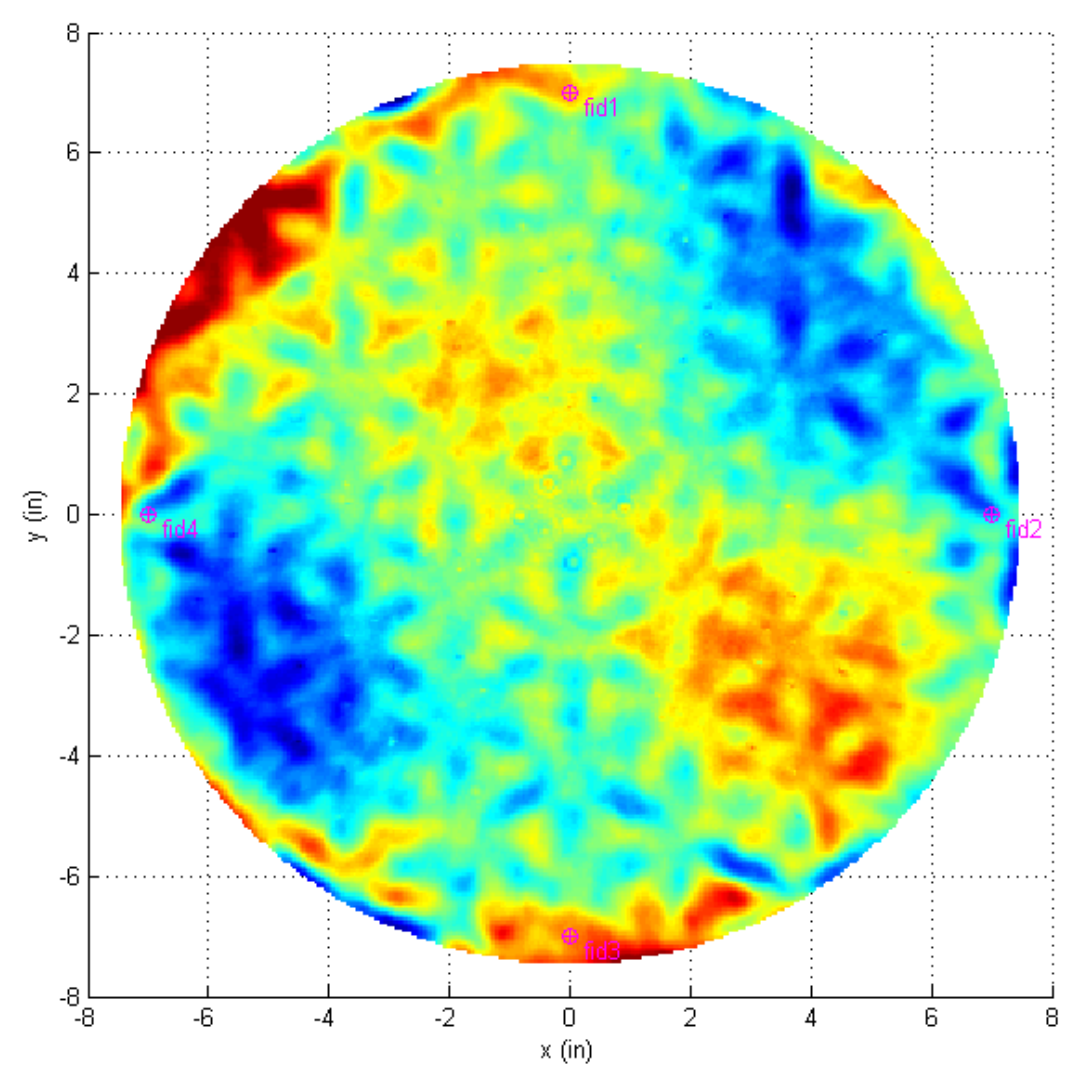

- Second ion cycle further reduced the global figure errors by an additional $68 \%$

- Pocket milled quilting becomes visible
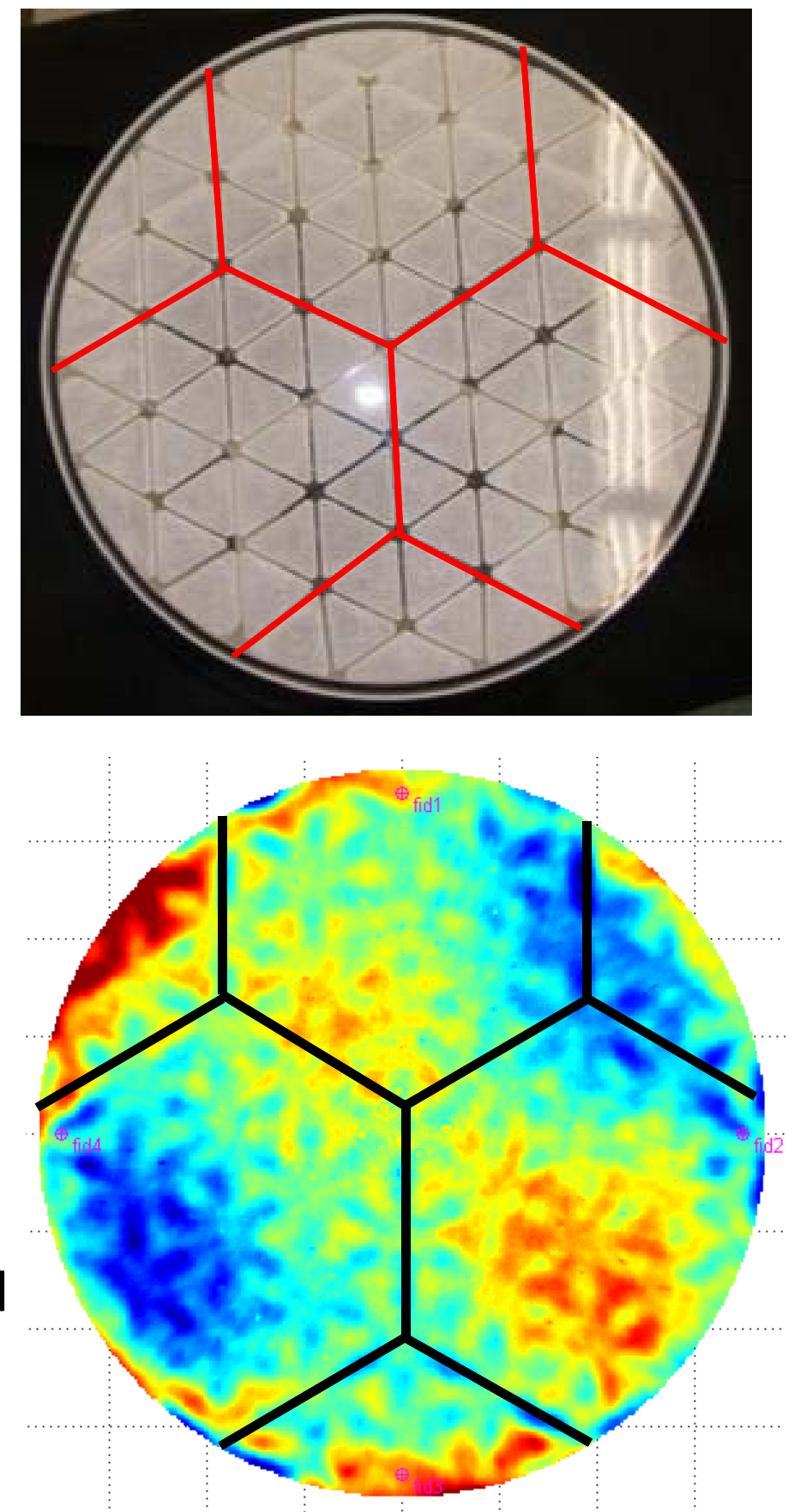


\section{Post Ion Figuring \#3}

\section{4nm RMS - 37nm P-V}

Power Removed

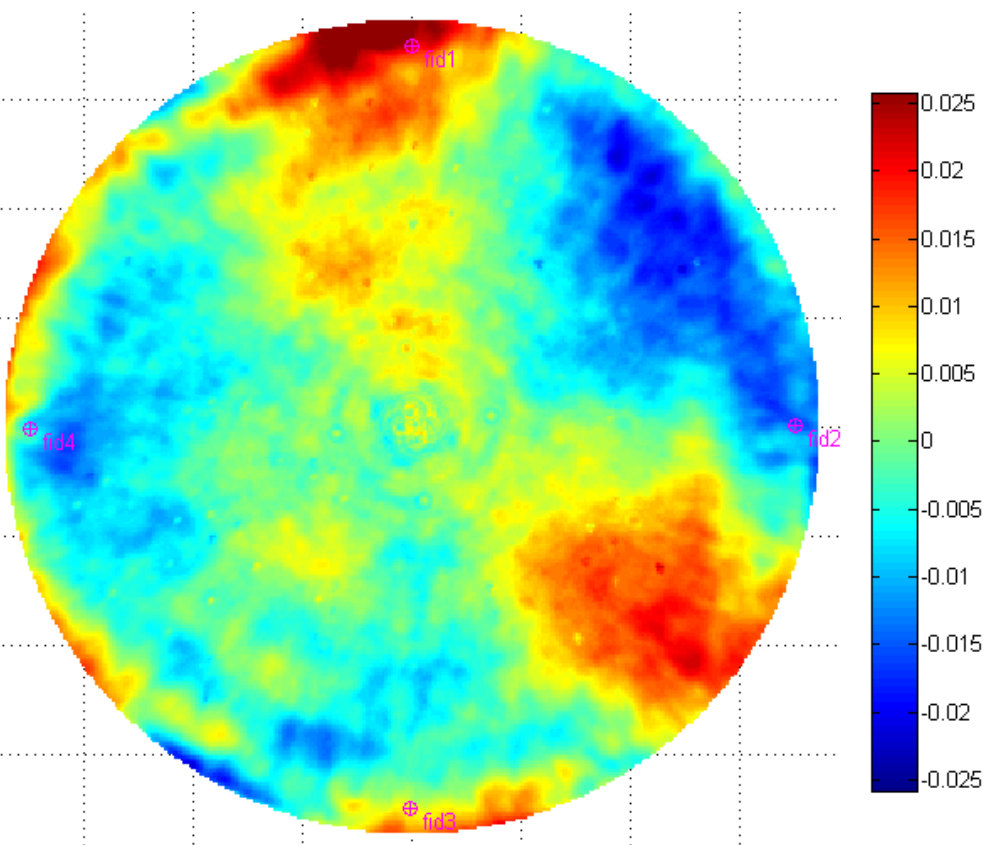

- Final ion figuring run focused on pocket quilting errors

- Mount repeatability limits overall surface quality

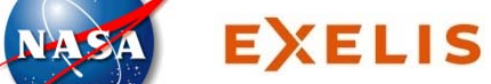

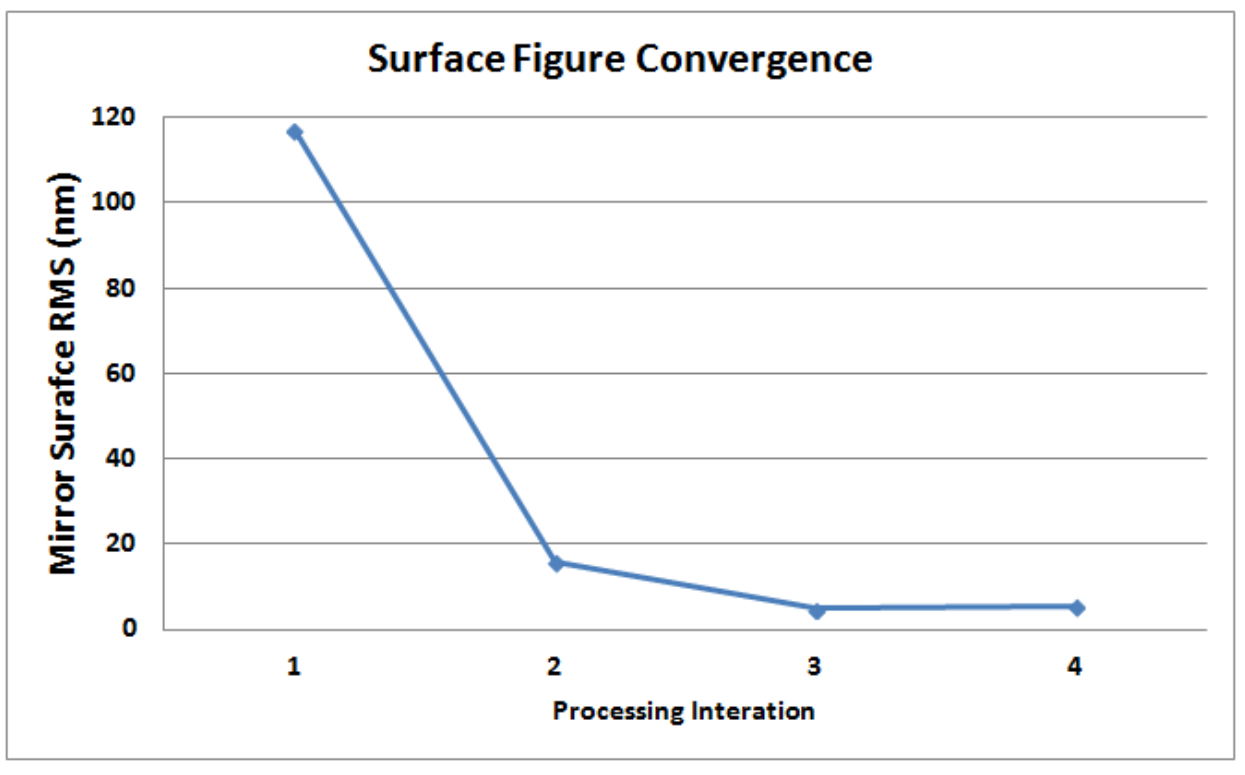

- Rapid convergence to final surface quality

- Deterministic processes reduce schedule time
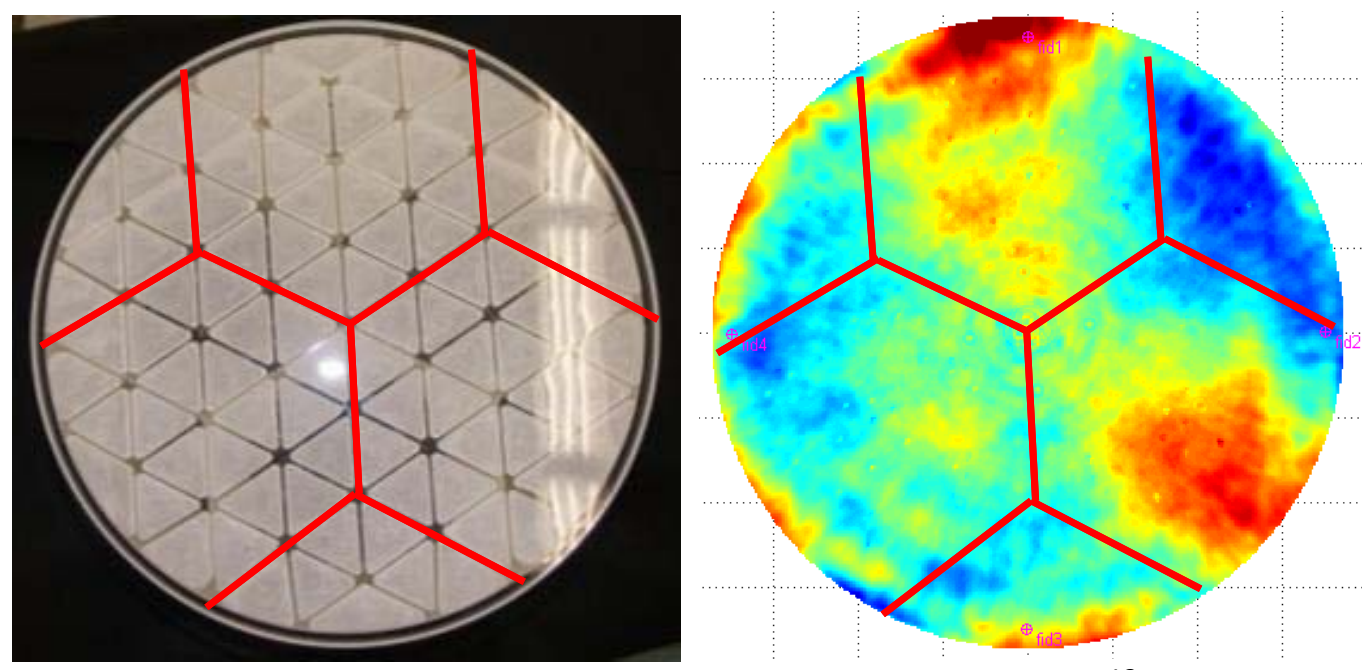


\section{AMTD PSD Testing Summary}

- Data collected using Zygo Verifire and White Light Interferometer

- Ion Figuring successfully removed most of the polishing quilting artifacts

- Results show no significant PSD change due to ion figuring in spatial periods smaller than $20 \mathrm{~mm}$.
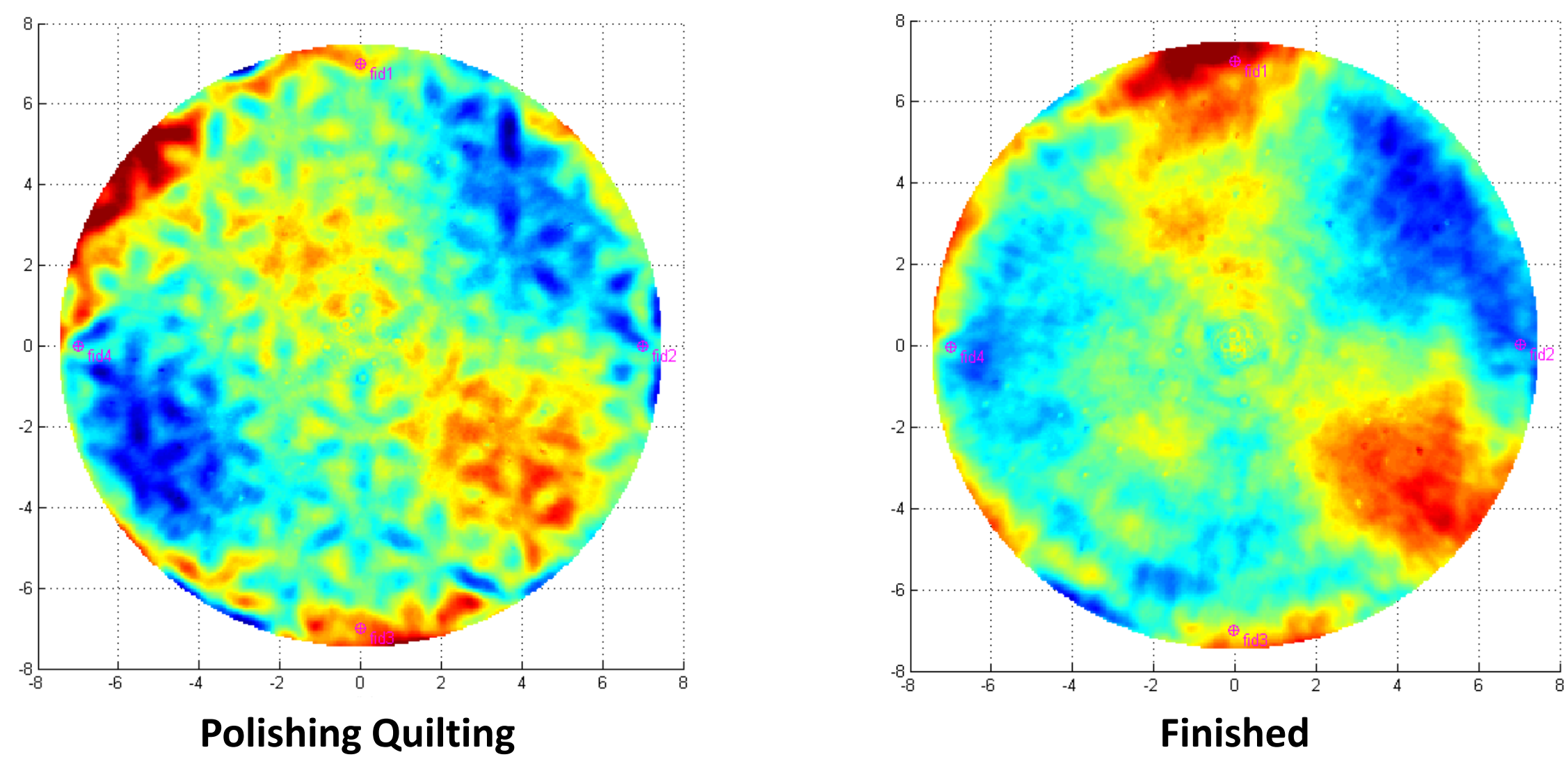


\section{0mm FFT Low Pass Filter (Final Ion Iteration)}

Before Ion Figuring

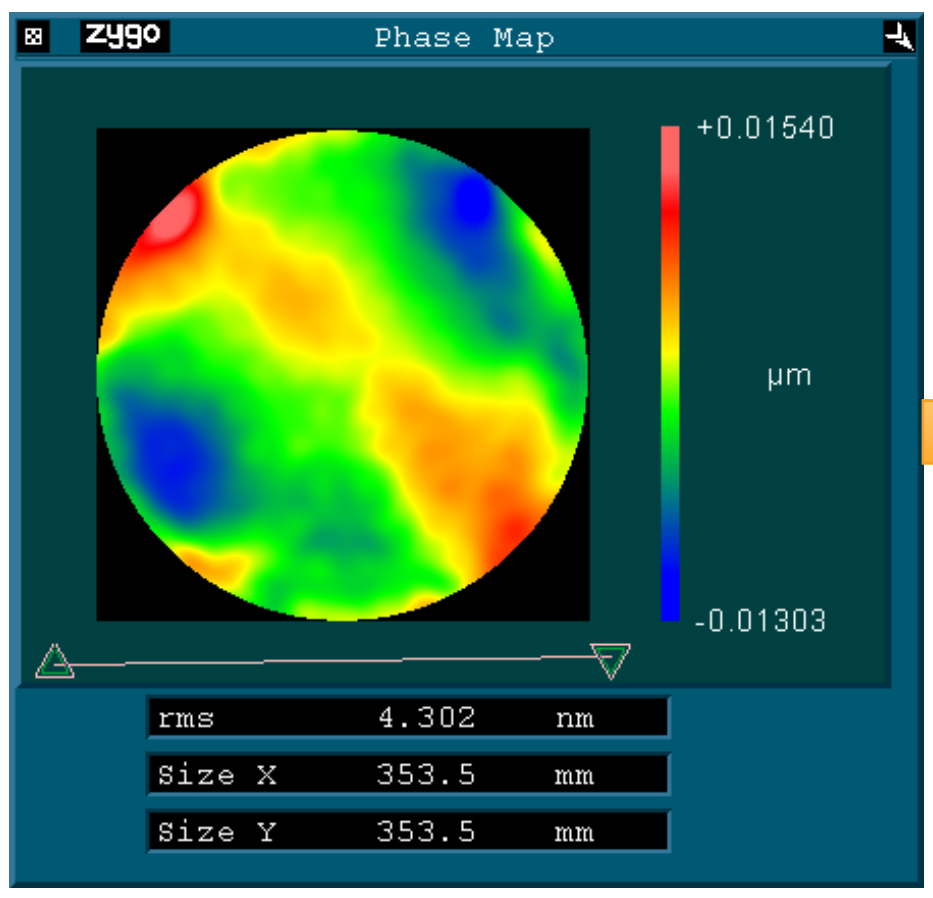

After Ion Figuring

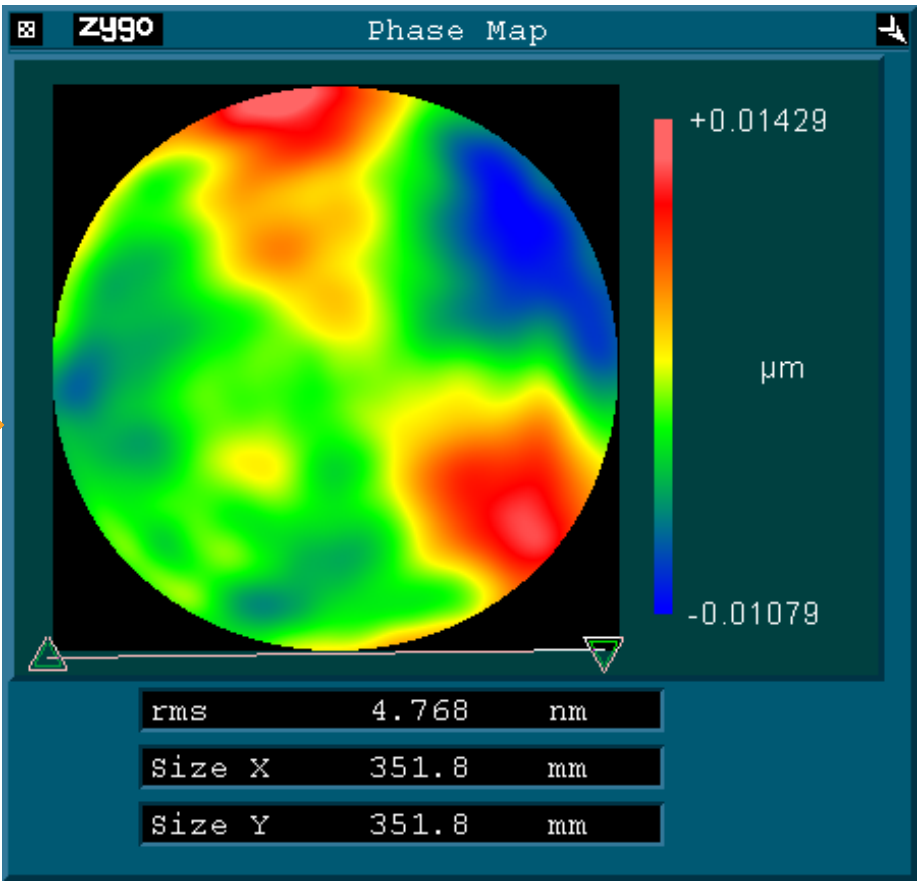

$>$ Low order figure error has reached the current metrology reproducibility limit in the current configuration leading to no improvement in figure errors with spatial periods longer than $50 \mathrm{~mm}$

$>$ Low order figure error present in the measurement after ion figuring is driven by mount reproducibility

$>$ Metrology reproducibility and accuracy could be improved with an optimized mount design and additional part rotations 


\section{0mm-10mm FFT Band Pass Filter (Final Ion Iteration)}

Before Ion Figuring

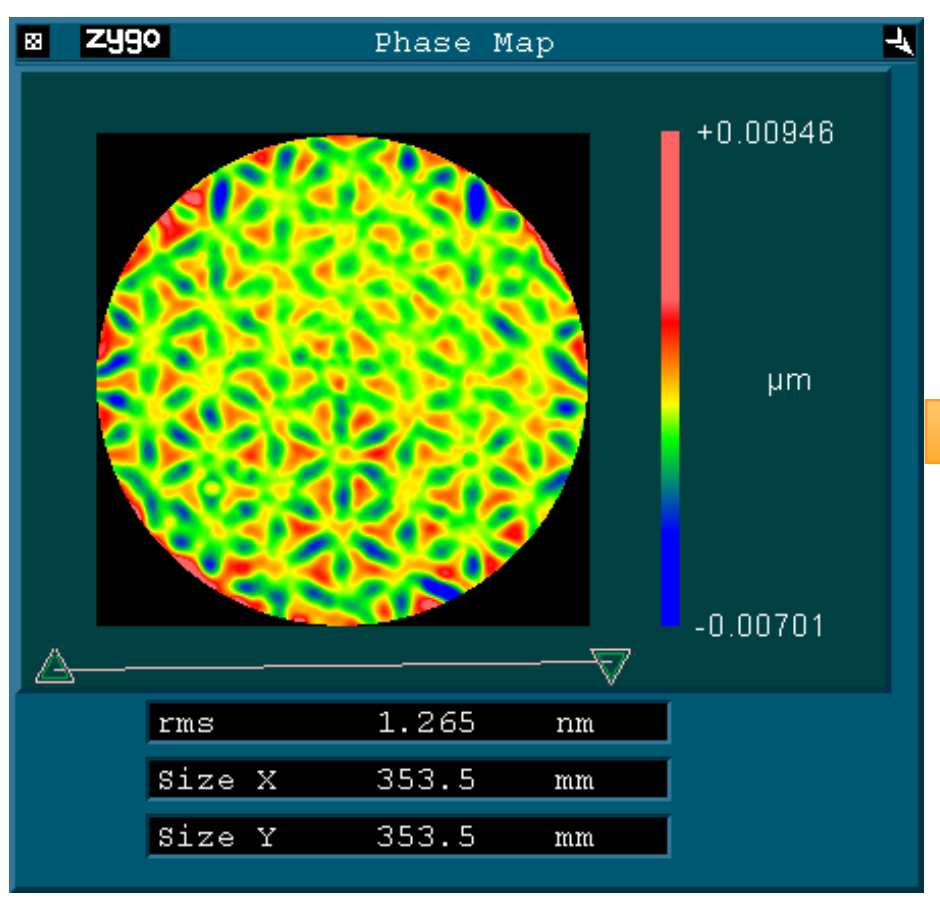

After lon Figuring

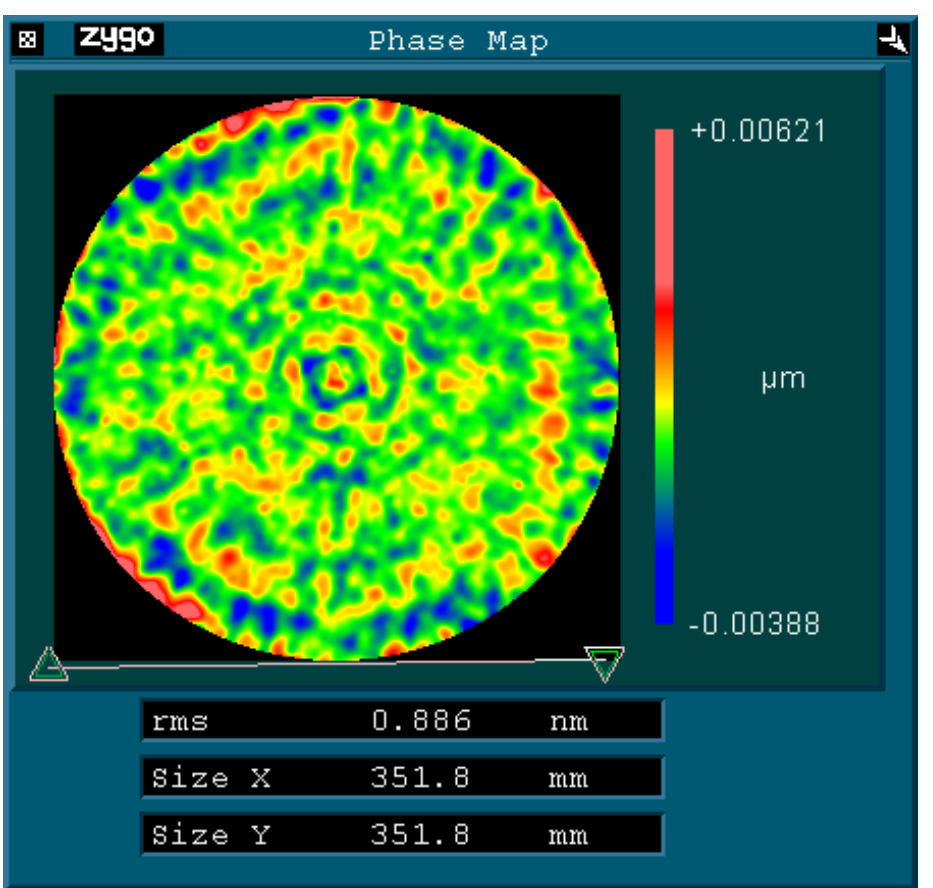

$>$ The quilting period appears at $\sim 20-30 \mathrm{~mm}$ spatial periods before final ion figuring

$>$ Ion figuring improved the rms in the $50-10 \mathrm{~mm}$ spatial period band eliminating most of the quilting structure 


\section{0mm FFT High Pass Filter (Final Ion Iteration)}

Before Ion Figuring

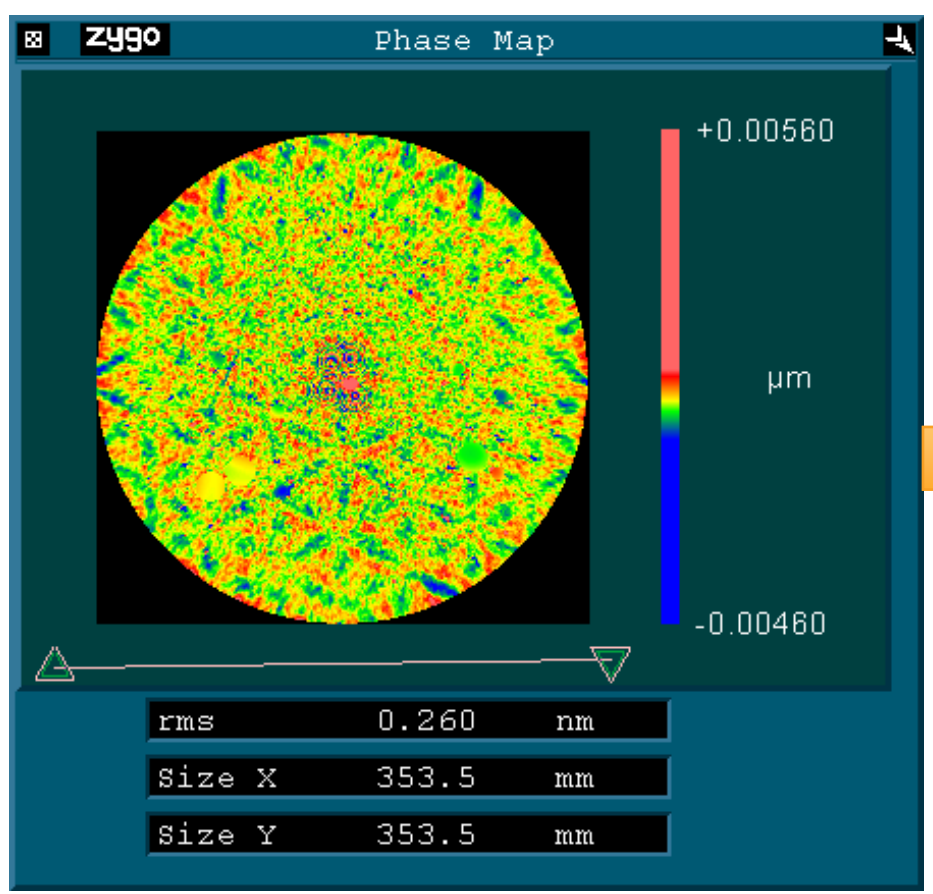

After lon Figuring

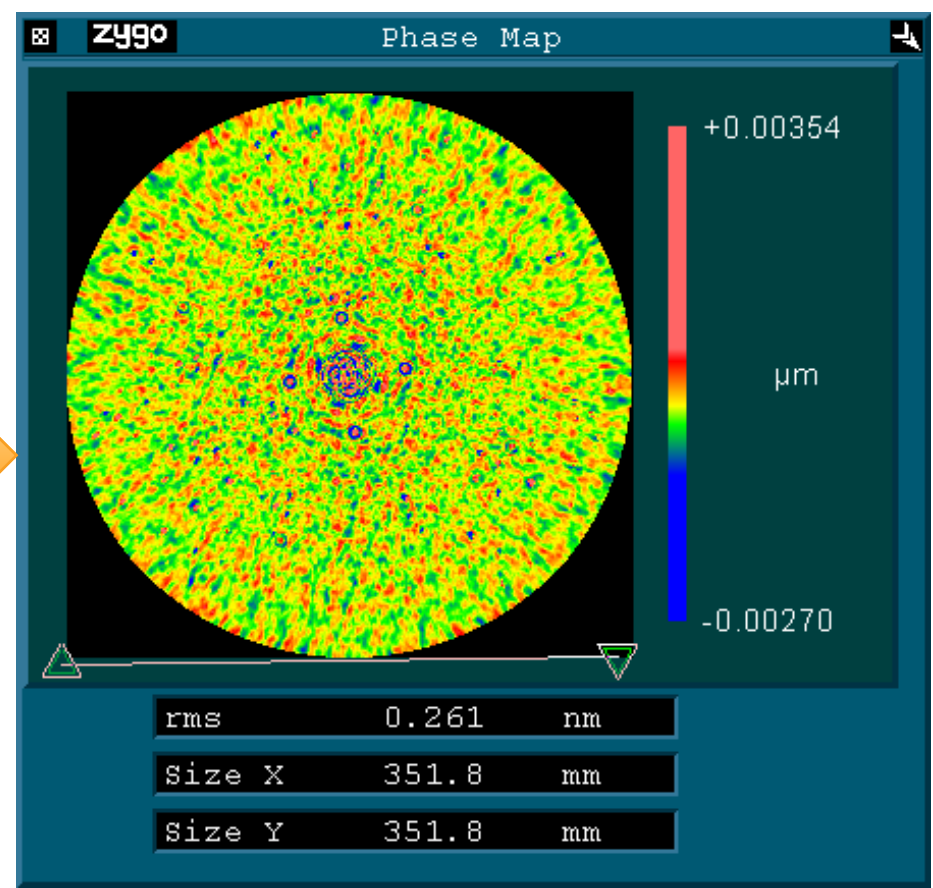

$>$ The shorter spatial periods, $<10 \mathrm{~mm}$, were negligibly affected by ion figuring

$>$ Super polishing to improve the micro-roughness could be done if needed for the UV application

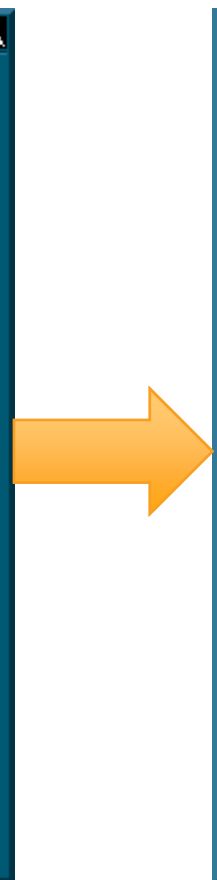




\section{AMTD PSD Assessment (Final Ion Iteration)}

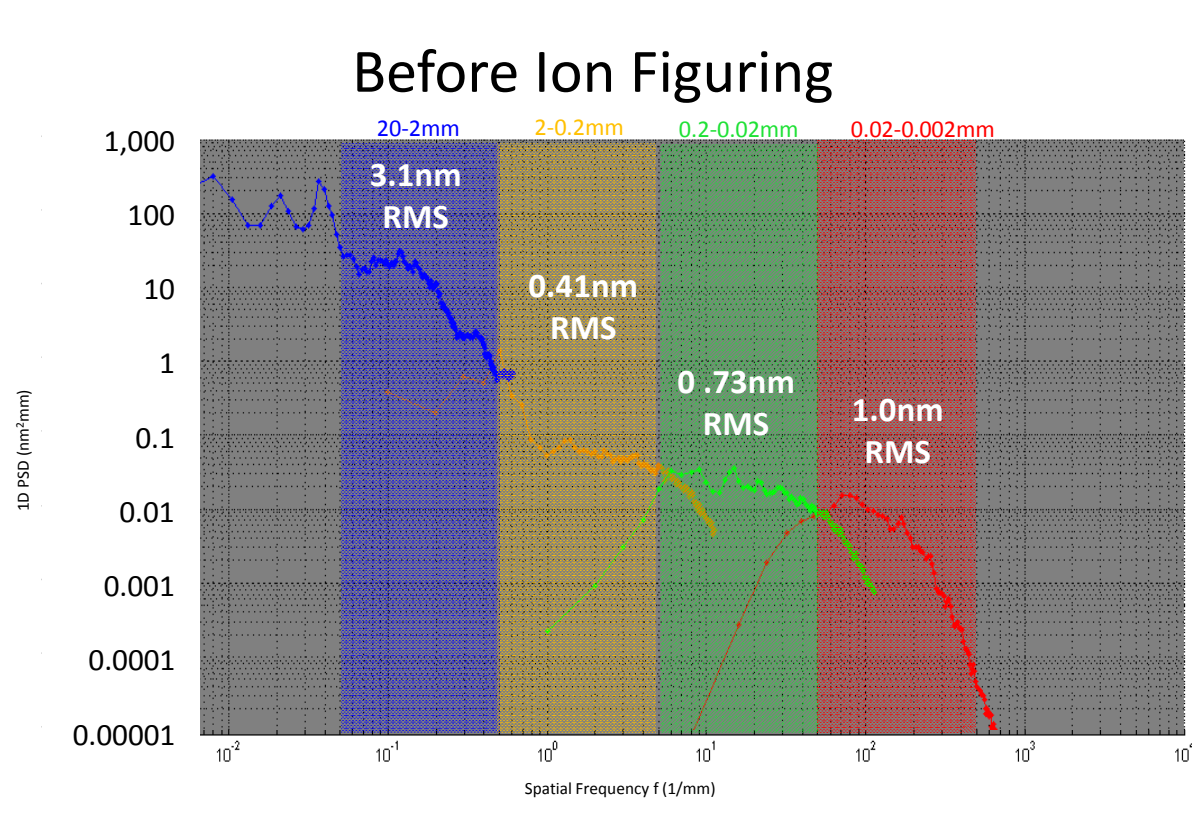

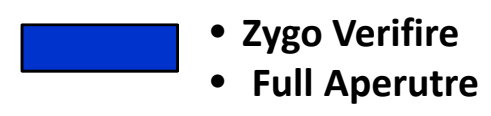

- Full Aperutre

- Zygo NewView

- 1X Objective; $0.5 \mathrm{X}$

relay

- $10 \mathrm{~mm}$ aperture; 22um pixel

After lon Figuring
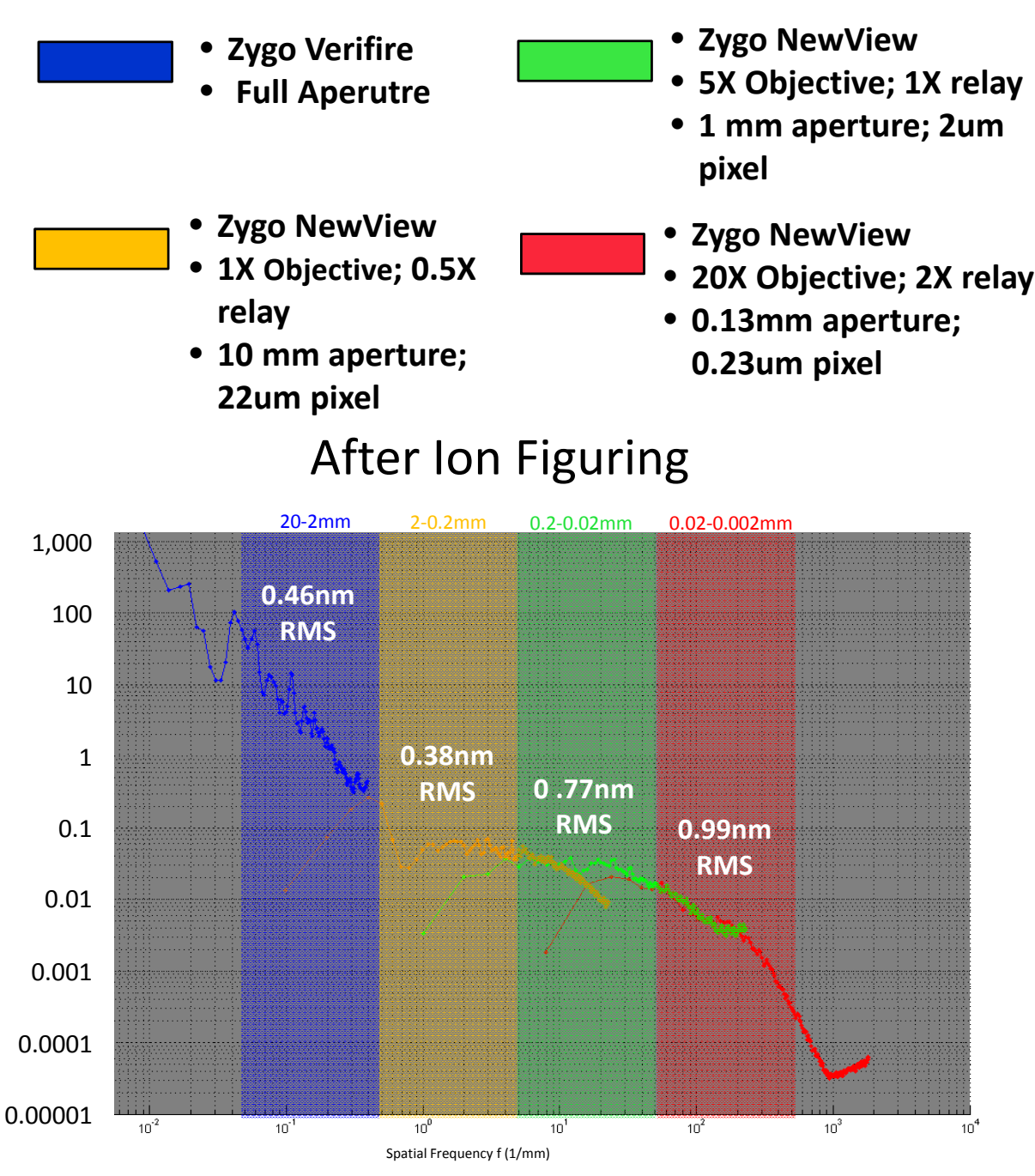

pixel

- Zygo NewView

- 20X Objective; $2 X$ relay

- $0.13 \mathrm{~mm}$ aperture;

0.23 um pixel

Bands were analyzed at $>5 \mathrm{X}$ above Nyquist limit with $\sim 5$ cycles per test aperture

$>$ Hanning window used for PSD analysis with magnitude re-scale

$>$ Spatial periods smaller than $20 \mathrm{~mm}$ were negligibly affected by ion figuring as evident in the PSD plot 


\section{1m x 3m Optical Test Chamber at MSFC was used for cold}

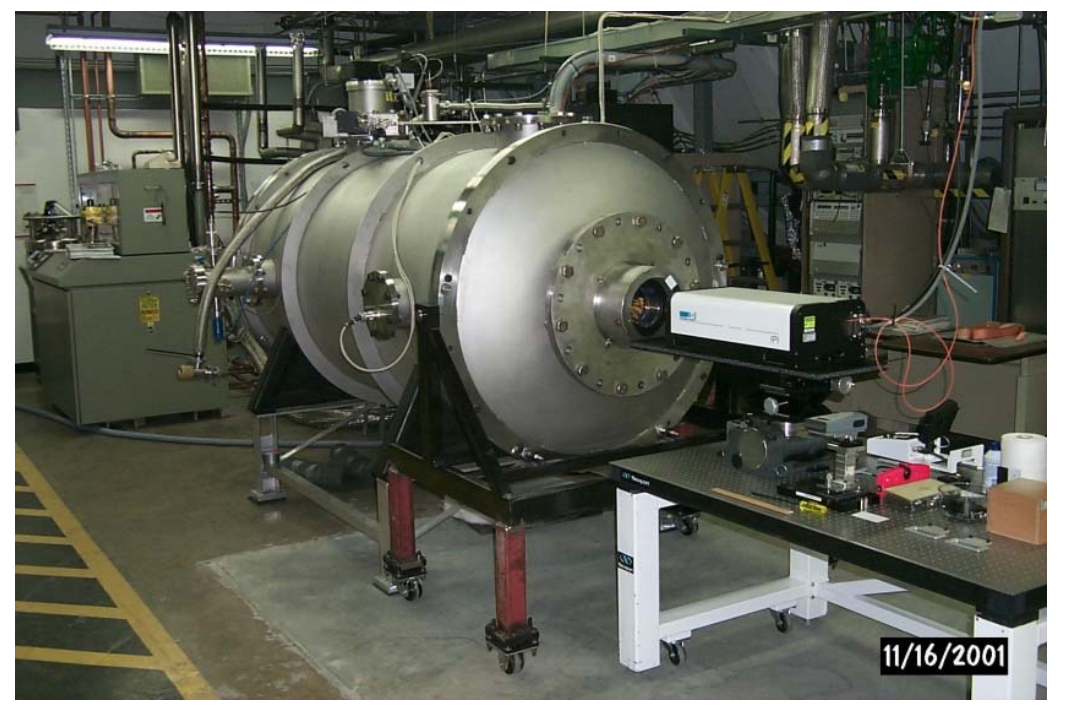

- Vacuum Chamber: 1x3 m cylinder with helium shroud.

- Optical View Ports: BK7 window; 150 mm dia. clear aperture.

- Precision stage to provide interferometer pointing and alignment.

- Operational Pressure: < 5 E-6 Torr

- Temperature Range: 300 to $12 \mathrm{~K}$

- Typical cryo optical test: $290,200,100,70,50,30 \mathrm{~K}, 2$ cycles; 3 weeks duration.

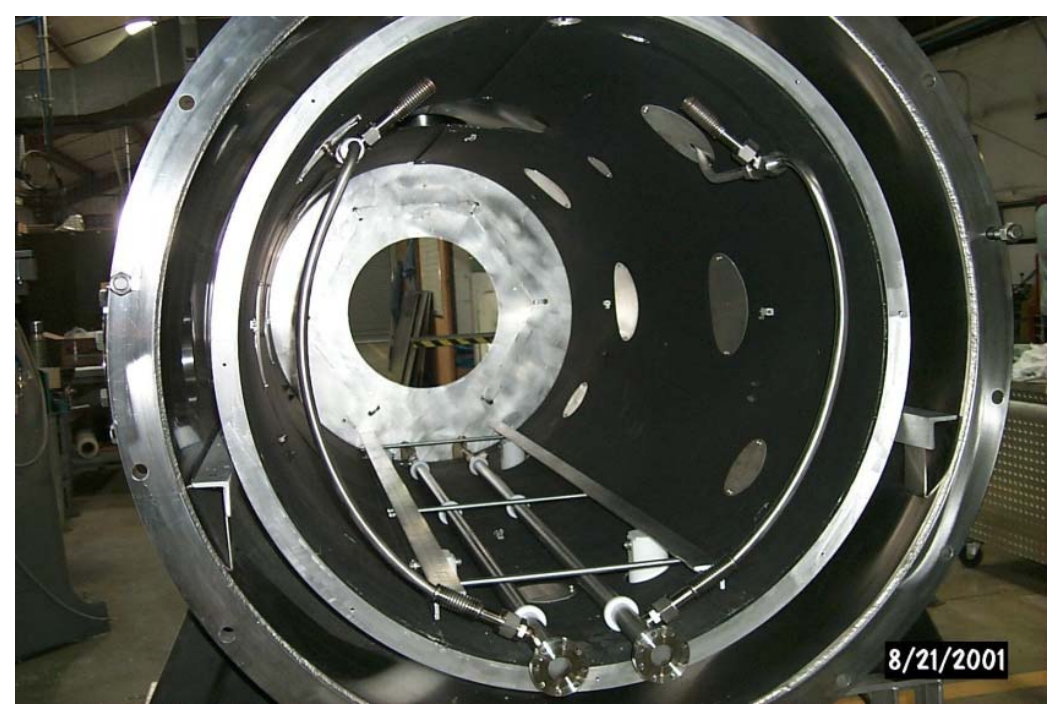

Cryooptical Test Chamber

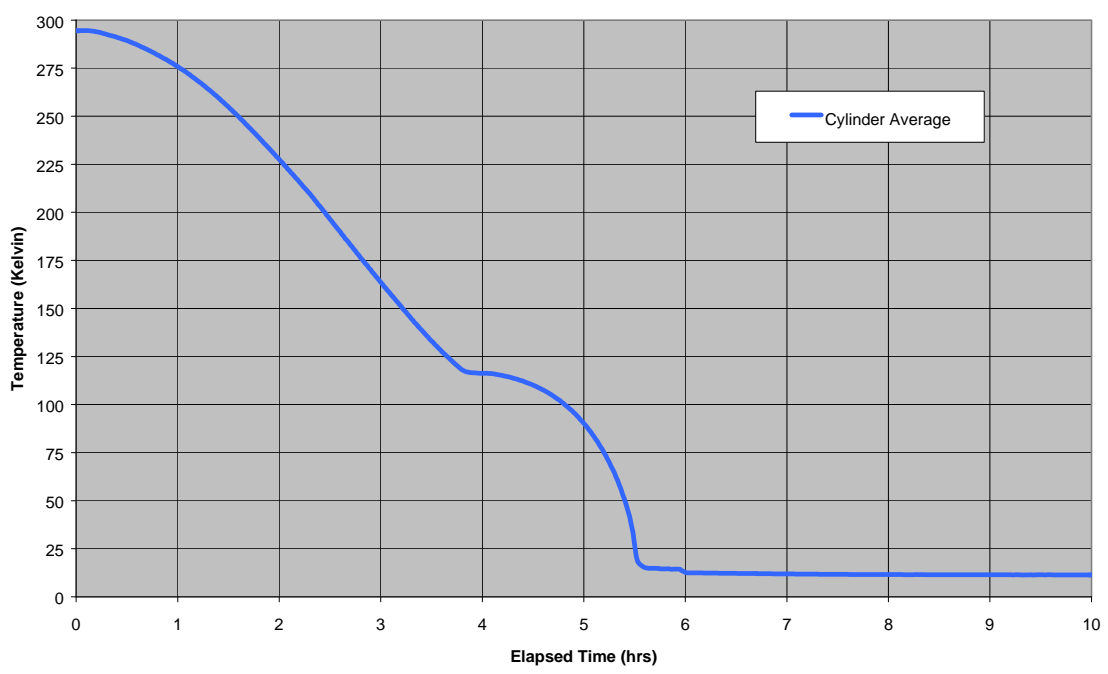




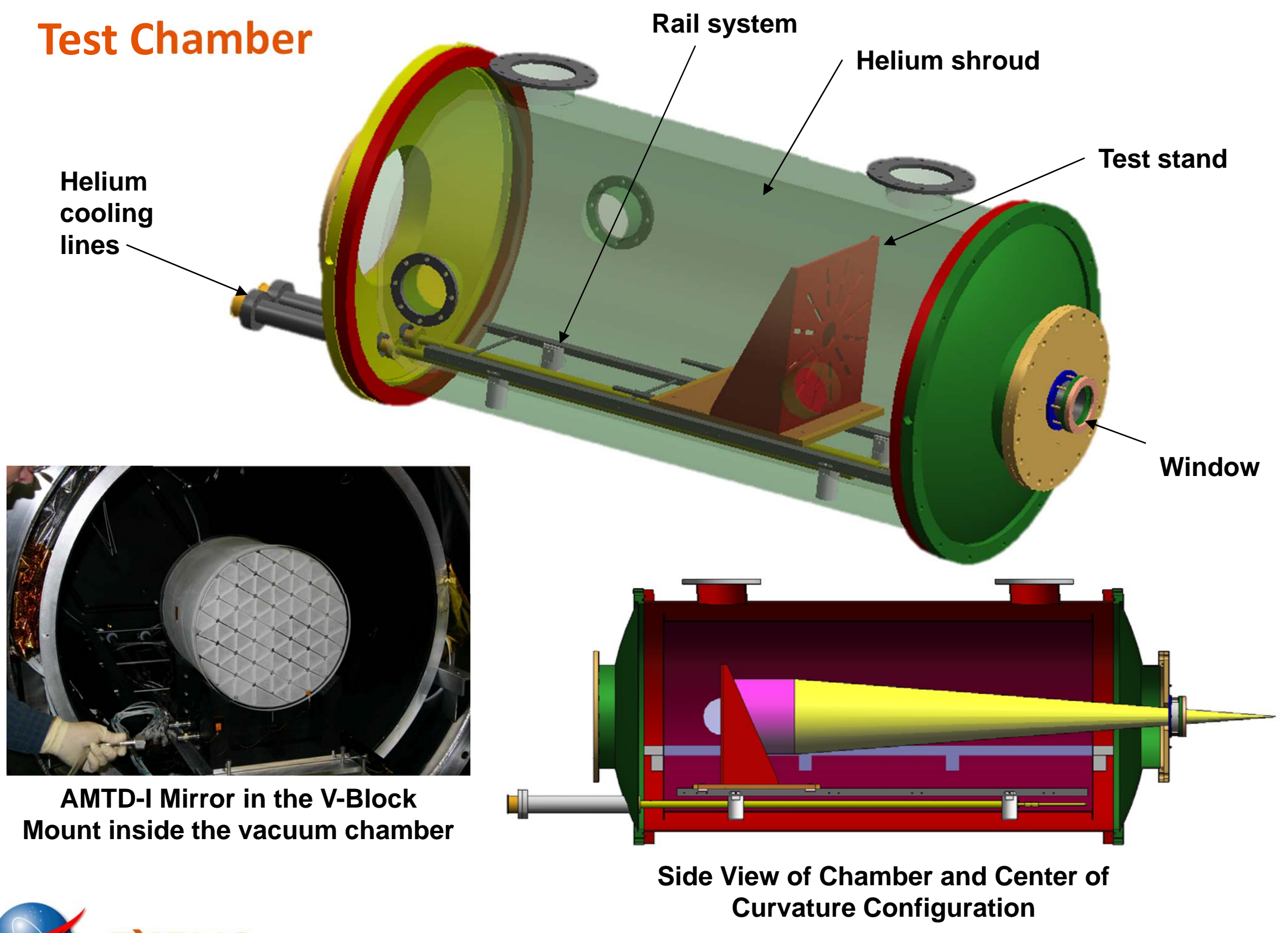

NASA EXELIS 


\section{Thermal IR image During Temperature Transition}
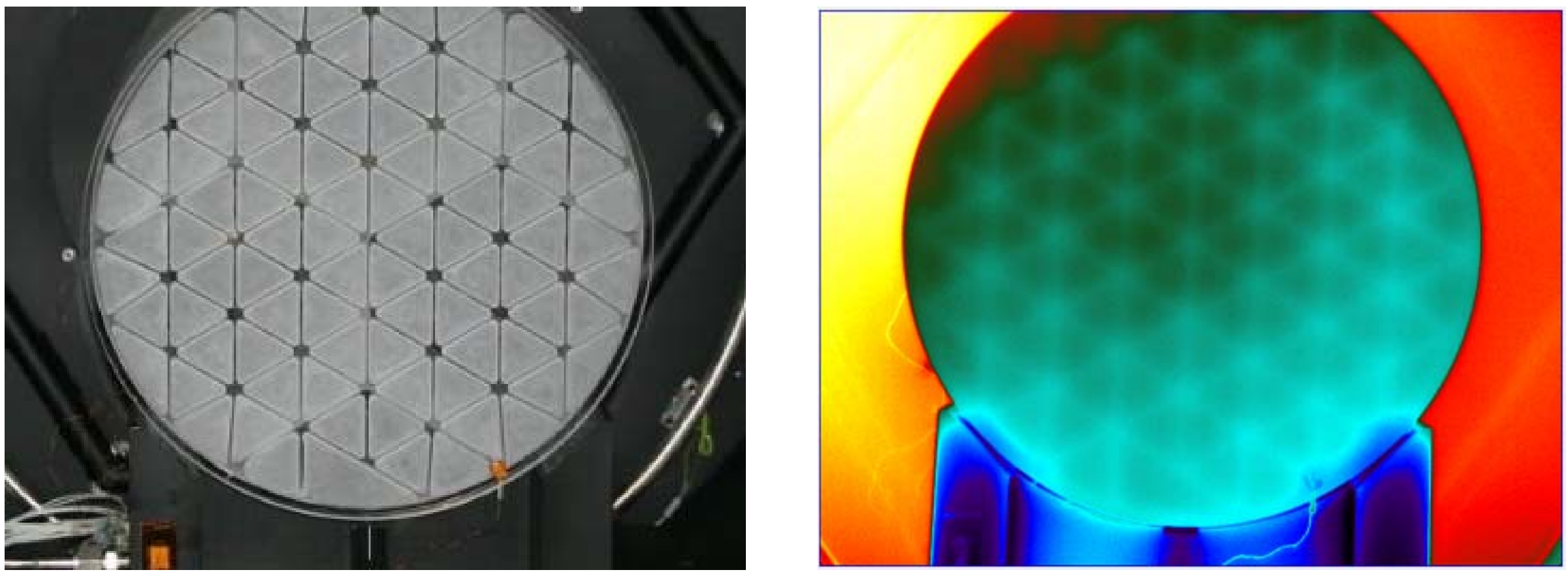

- FLIR SC655 640x480 16-bit uncooled microbolometer

- 7.5-14 $\mu \mathrm{m}$ spectral range.

- A 130mm clear aperture ZnSe window.

- IR image recorded on 1st cryo cycle @ 285K during warmup 


\section{Typical Cold Cycle for Optical Testing}

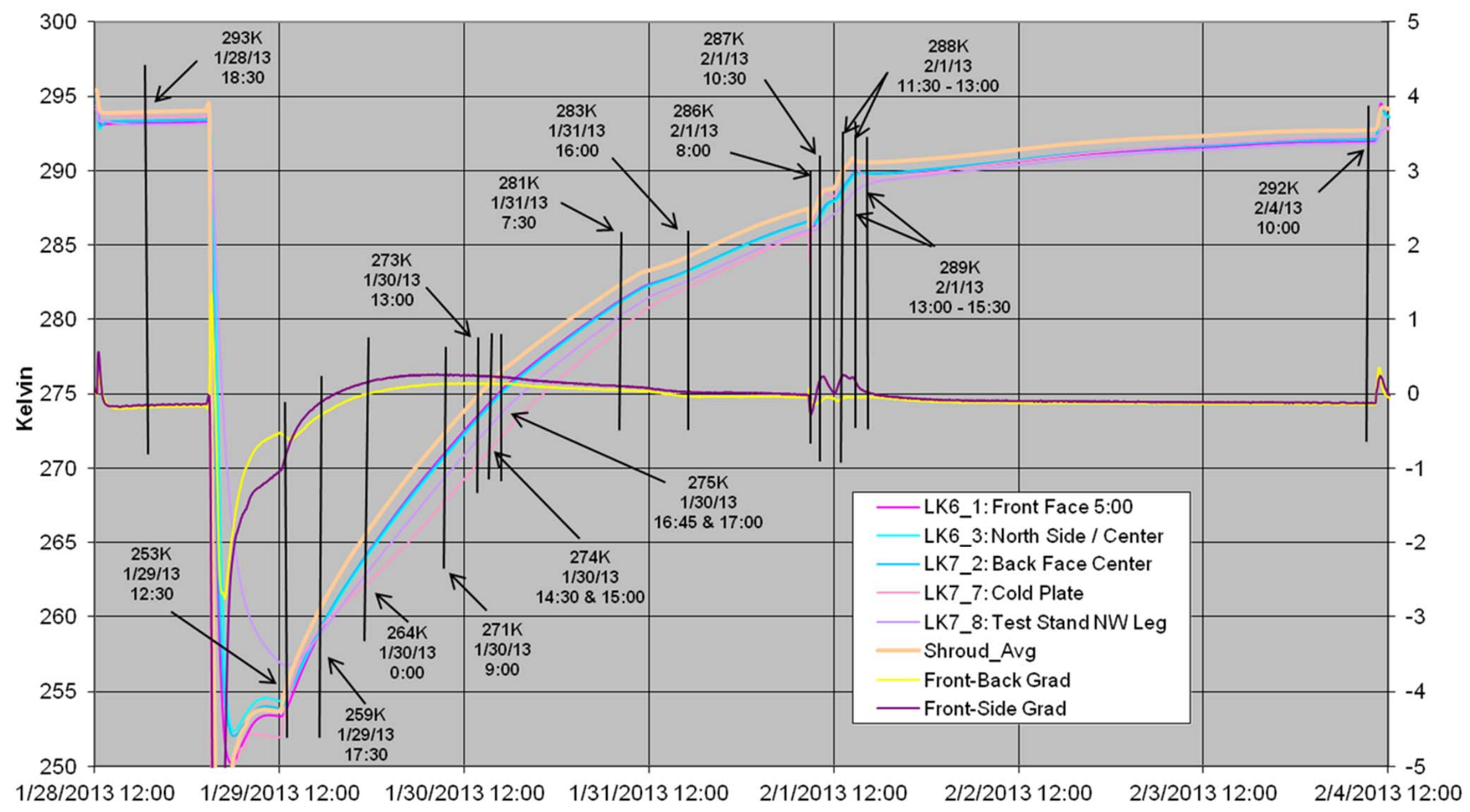

- Mirror temperature stabilize overnight for minimum gradient.

- Optical measurements at 255K, 265K, 275K, 285K and ambient. 


\section{Thermal Changes from Room Temperature}
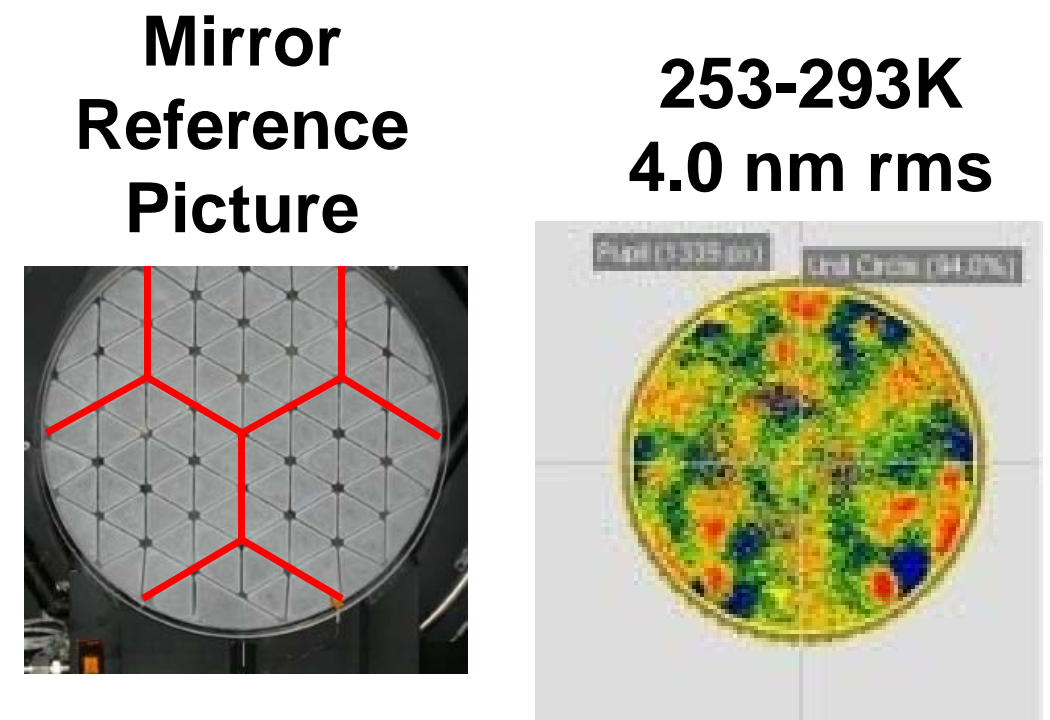

273-293K

$3.7 \mathrm{~nm}$ rms

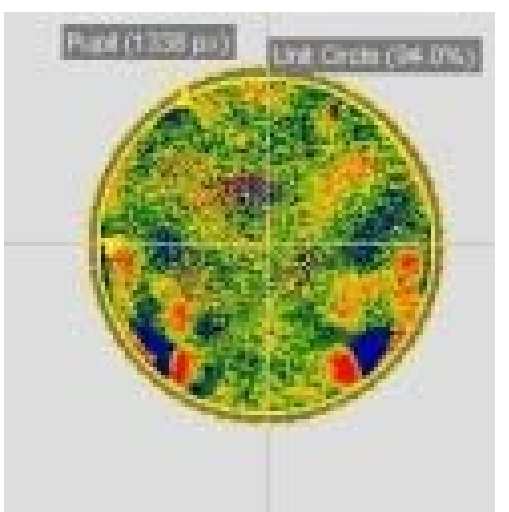

286-293K

$3.6 \mathrm{~nm}$ rms

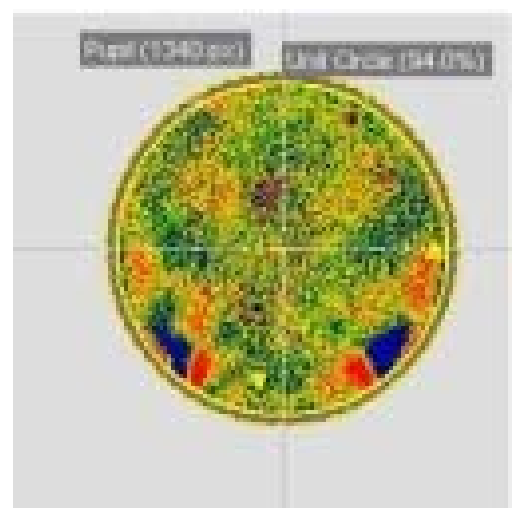

- Thermal gradients allowed to stabilize overnight

- Very small changes in surface figure were observed during thermal testing down to 253K

- Figure change was dominated by the non-kinematic V-block mount 


\section{Thermal Gradients Driven into Mirror}

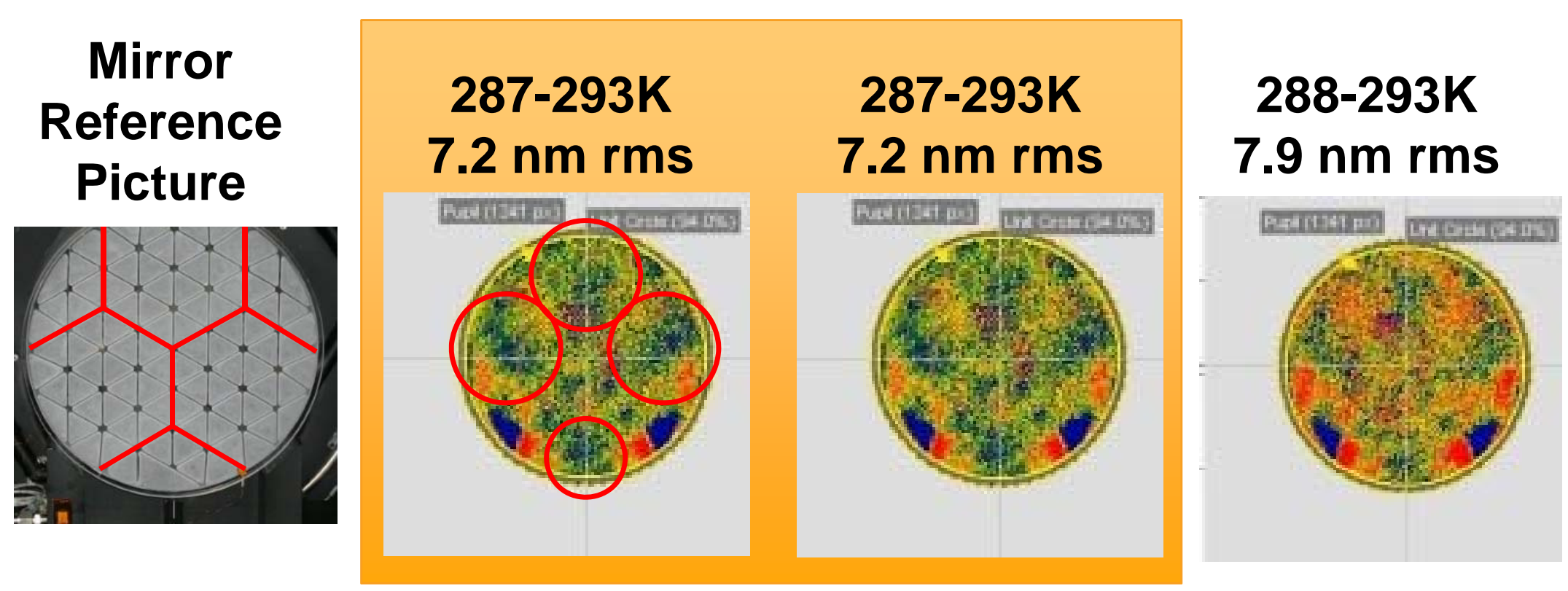

- Thermal gradients driven into mirror during temperature transitions

- Changes were larger due to gradients in the mirror structure

- Figure change was still dominated by the non-kinematic V-block mount 


\section{5m, AMTD Phase II Mirror Program}

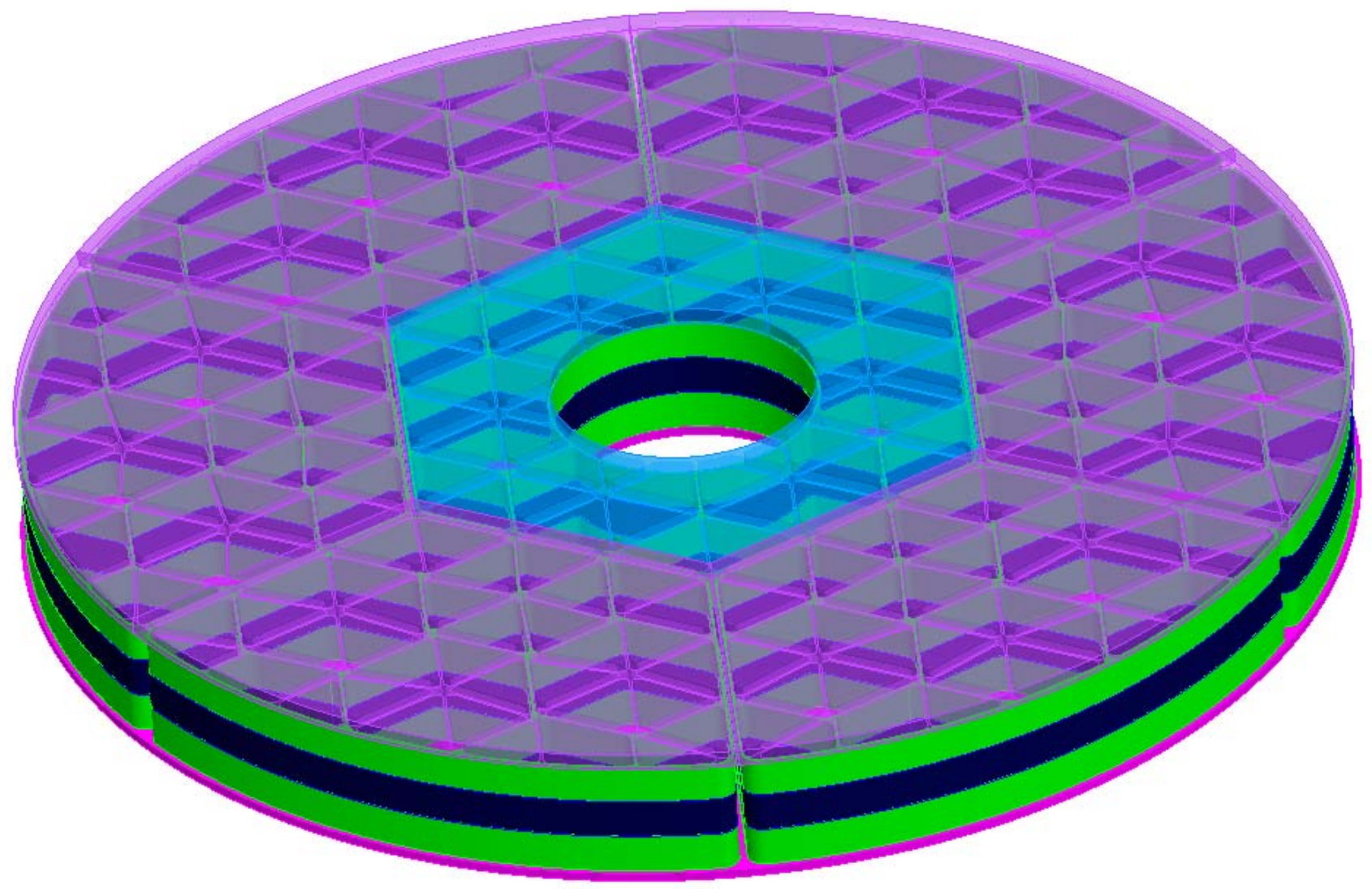

- Phase II Contract awarded to the NASA/Exelis team

- Plan to build and test a $1.5 \mathrm{~m}$ on-axis mirror using the stacked core approach

- Mirror Blank will be fabricated in 2015 


\section{AMTD Testing Summary}

- Processing of the stacked core mirror converged very quickly using ion figuring

- Results show no significant PSD change due to ion figuring in spatial periods smaller than $10 \mathrm{~mm}$.

- Global surface figure limited by mount repeatability

- Demonstrated that UV quality ( $5 \mathrm{~nm}$ RMS) could be achieved and verified

- During cycle 3, heat was introduced after 286K measurements to induce thermal gradient, resulting in higher residual rms values for $287 \mathrm{~K}$ and $288 \mathrm{~K}$.

- Minimal surface deformation seen during steady state thermal transition.

- All work performed under NASA contract number NNM12AA02C

- COTR: Michael R. Effinger 